Victor Ferreira de Ávila

\title{
Modelo de hipertensão arterial decorrente do bloqueio de $N F-K B$ durante a nefrogênese: efeito da sobrecarga salina
}

Tese apresentada à Faculdade de Medicina da Universidade de São Paulo para obtenção de título de Doutor em Ciências

Programa de Nefrologia

Orientadora: Dra Clarice Kazue Fujihara

São Paulo 
Victor Ferreira de Ávila

\section{Modelo de hipertensão arterial decorrente do bloqueio de $N F-K B$ durante a nefrogênese: efeito da sobrecarga salina}

Tese apresentada à Faculdade de Medicina da Universidade de São Paulo para obtenção de título de Doutor em Ciências

Programa de Nefrologia

Orientadora: Dra Clarice Kazue Fujihara

São Paulo 
Dados Internacionais de Catalogação na Publicação (CIP)

Preparada pela Biblioteca da

Faculdade de Medicina da Universidade de São Paulo

Creprodução autorizada pelo autor

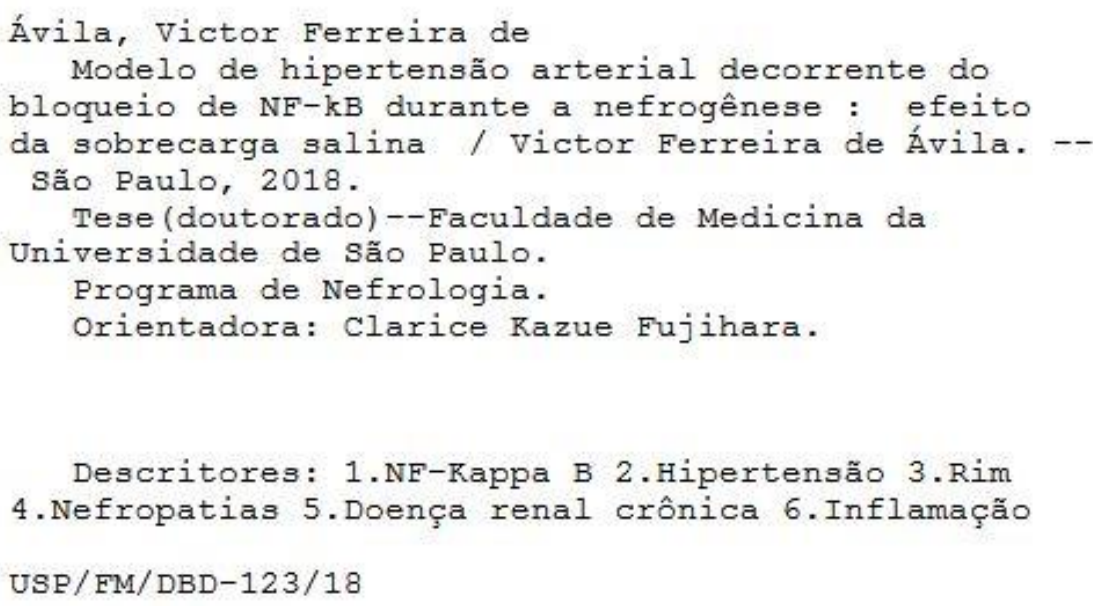

Responsável: Kátia Maria Bruno Ferreira - CRB-8/6008 


\section{AGRADECIMENTOS}

Quero agradecer à minha orientadora Dra. Clarice Kazue Fujihara por todos os ensinamentos, pela compreensão, paciência e pela disposição em auxiliar no desenvolvimento deste trabalho. Sem sua força e dedicação esse projeto não seria possível.

Ao Prof. Dr. Roberto Zatz pela oportunidade de trabalhar em seu laboratório, pela atenção e pelos ensinamentos.

Ao Prof. Dr Niels por todos os ensinamentos, conselhos e ideias que tanto contribuíram para o desenvolvimento deste trabalho.

À Dra Denise Malheiros pela enorme colaboração nesse projeto.

Ao Dr. Joel, Dra. Vanda e Dra. Rosa que muito me ensinaram ao longo destes anos.

À Dra. Simone da Costa Alarcon Arias por me acompanhar desde a iniciação científica até o doutorado, sempre me ajudando, compartilhando seus conhecimentos e sendo muito paciente.

Ao também pós-graduando e grande amigo Orestes Foresto Neto, pelos anos de amizade, parceria e a imensa colaboração na realização deste trabalho.

Ao grande amigo Rafael Canavel que me acompanha desde o início da faculdade, iniciação científica e agora no doutorado.

Aos meus grandes amigos e companheiros de trabalho Amanda, Fernanda, Karin, Lisienny, Viviane e Carol por todo a ajuda e companheirismo durante todos esses anos.

Aos alunos de iniciação científica, mestrado, doutorado e pós-doutorado do Laboratório de Fisiopatologia Renal (LIM 16) pela companhia, amizade e por me ajudarem na realização deste trabalho. 
Aos funcionários do LIM 16, em especial à Janice, Cláudia, Luciene, Luzia, Vagner, Solange, Newton e Ivone, pelos ensinamentos, pela dedicação e por contribuírem grandemente para a realização deste trabalho.

Aos meus pais Paulo Roberto Ávila de Oliveira e Selma Ferreira de Souza Ávila, aos meus irmãos e todos os familiares, por todo apoio, dedicação e por serem sempre um porto seguro.

Agradeço especialmente a minha namorada Marillia Nicácio Dalla Pria por todo o amor, companheirismo, dedicação e por todos os bons momentos que vivemos e vamos viver.

À FAPESP (proc no. 2012/10926-5) e a CNPq (303684/2013-5) pelo apoio financeiro que possibilitou a realização deste trabalho. 
Escreva sua história pelas suas próprias mãos 


\section{SUMÁRIO}

Lista de abreviaturas

Lista de tabelas

Lista de Figuras

Resumo

Abstract

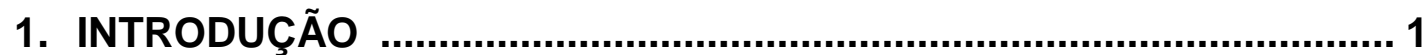

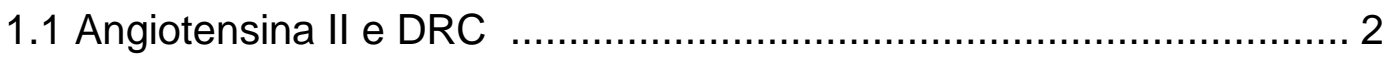

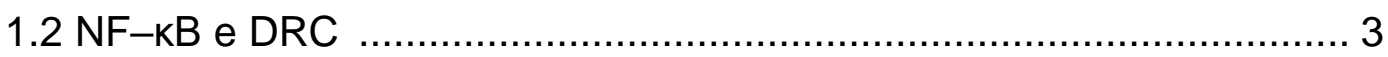

1.3 Angiotensina II e NF-kB na nefrogênese .................................. 4

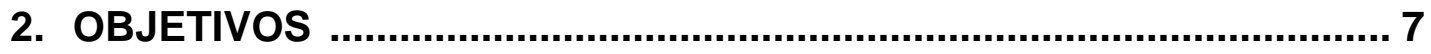

3. MATERIAIS E MÉTODOS ............................................................ 8

3.1 Obtenção do modelo experimental ............................................. 8

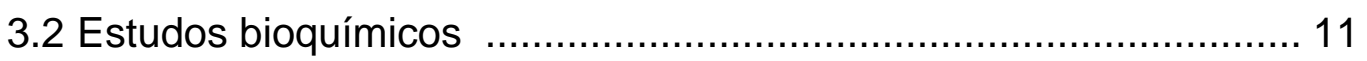

3.3 Estudo histológico do tecido renal ......................................... 12

3.4 Quantificação da interleucinas (ELISA) ................................... 13

3.5 Estudo imuno-histoquimico do tecido renal ................................ 13

3.6 Análise do conteúdo proteico do tecido renal (Western Blot) ......... 17

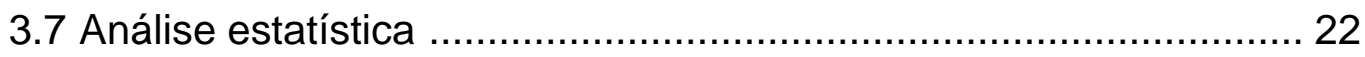

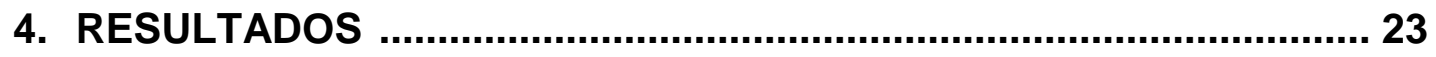

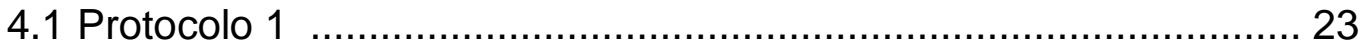

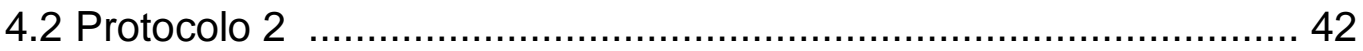

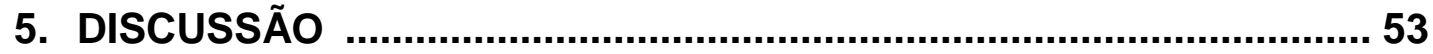

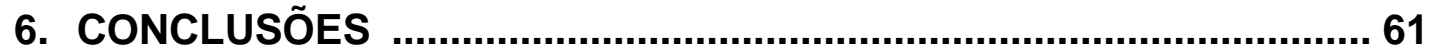

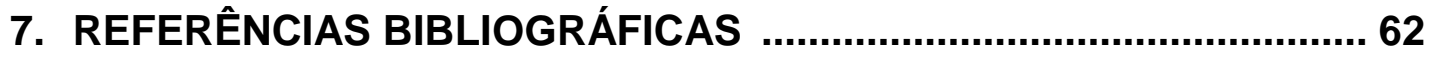




\section{LISTA DE ABREVIATURAS}

\section{Abreviatura}

DRC

PDTC

HA

UNx

SS

NS

SRAA

All

$E G$

LA

MCP-1

$\mathrm{M} \phi$

Int

Glo

Art

INT

Col-1

TLR4

IL-6

$\mathrm{HO}-1$

MnSOD

\section{Significado}

Doença renal crônica

Pirrolidina ditiocarbamato

Hipertensão arterial

Uninefrectomia

Sobrecarga salina

Dieta padrão

Sistema renina-angiotensina-aldosterona

Angiotensina 2

Esclerose glomerular

Lesões arteriolares

Monocyte Chemoattractant Protein-1

Macrófago

Interstício

Glomerular

Arteriolar

Expansão do interstício renal

Colágeno-1 intersticial

Toll-like receptor 4

Interleucina-6

Heme oxygenase 1

Mitochondrial antioxidant

manganese superoxide dismutase 2 


\section{LISTA DE TABELAS}

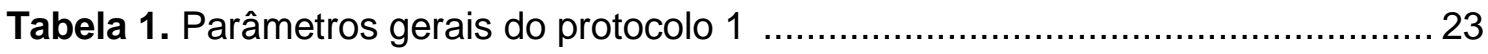

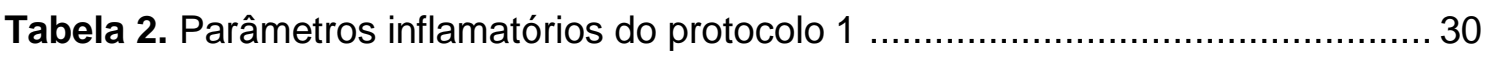

Tabela 3. Vias de sinalização intracelular e estresse oxidativo no protocolo 1 ...........37

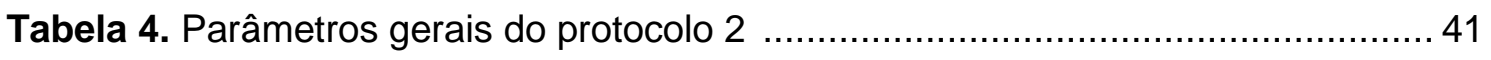

Tabela 5. Parâmetros inflamatórios do protocolo 2 .................................................. 45

Tabela 6. Vias de sinalização intracelular a estresse oxidativo do protocolo 2 ...........50 


\section{LISTA DE FIGURAS}

Protocolo 1:

Figura 1. Valores de pressão caudal, albuminuria e clearance de creatinina 24

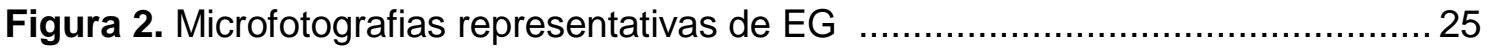

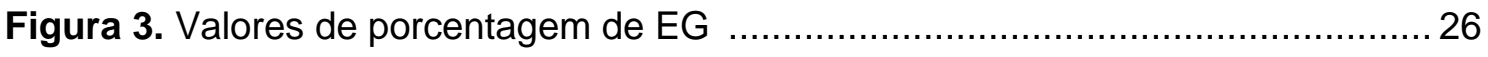

Figura 4. Microfotografias representativas de outros tipos de lesões glomerulares ...26

Figura 5. Microfotografias representativas de LA .............................................. 27

Figura 6. Valores porcentagem de LA ......................................................... 28

Figura 7. Microfotografias representativas da INT e Col-I ......................................29

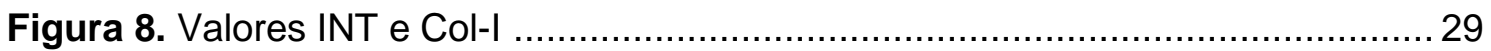

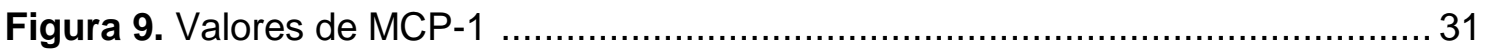

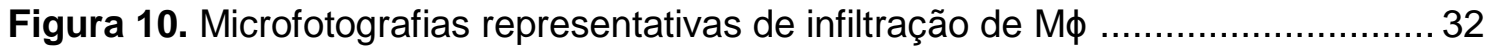

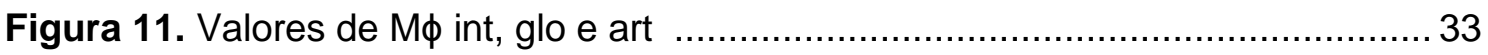

Figura 12. Microfotografias representativas de infiltração de linfócitos $T$.................... 34

Figura 13. Valores de linfócitos $T$ int, glo e art ................................................... 35

Figura 14. Microfotografias representativas de células positivas para All no int .........35

Figura 15. Valores de atividade plasmática de renina e células positivas para All ....36

Figura 16. Valores do conteúdo proteico renal de TLR4, p65 fosforilado e IL-6 .........37

Figura 17. Valores do conteúdo proteico renal de HO-1 e MnSOD2 ...........................39

Protocolo 2:

Figura 18. Valores de pressão caudal, albuminúria e clearance de creatinina ...........42 42

Figura 19. Microfotografias representativas de EG, LA, INT e Col-I ........................ 43

Figura 20. Valores de porcentagem de EG e LA ................................................. 44

Figura 21. Valores porcentagem de INT e Col-1 ............................................. 44

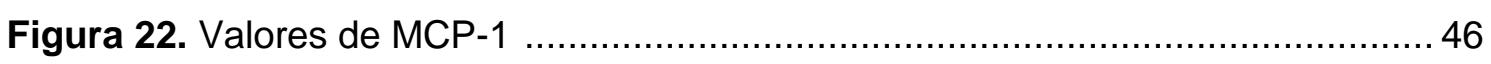

Figura 23. Microfotografias representativas de intiltração de $M \phi \ldots \ldots \ldots \ldots \ldots \ldots \ldots \ldots . . . . . . . . . . . . . . .46$

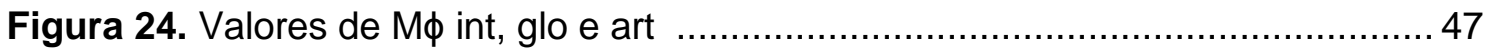

Figura 25. Microfotografias representativas de linfócitos $T$......................................48

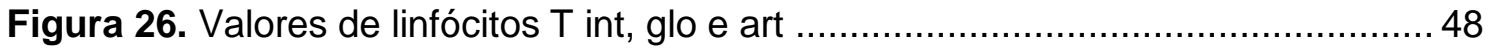

Figura 27. Microfotografias representativas de células positivas para All .................. 49

Figura 28. Valores de atividade plasmática de renina e células positivas para All .... 49

Figura 29. Valores do conteúdo proteico renal de TLR4, p65 fosforilado e IL-6 ........51

Figura 30. Valores do conteúdo proteico renal de HO-1 e MnSOD2 .......................... 52 


\section{RESUMO}

Ávila VF. Modelo de hipertensão arterial decorrente do bloqueio de NF-KB durante a nefrogênese: efeito da sobrecarga salina [tese]. São Paulo: Faculdade de Medicina, Universidade de São Paulo; 2018.

Recentemente descrevemos que ratos tratados com o inibidor do sistema NFKB pirrolidina ditiocarbamato (PDTC) durante a lactação desenvolvem uma hipertensão arterial na fase adulta, sem lesão renal aparente, caracterizando assim um novo modelo hipertensão essencial. No presente estudo, nós investigamos se a Uninefrectomia (UNx) associada a uma sobrecarga salina (SS) na dieta revelaria uma possível disfunção renal, agravando assim a hipetensão arterial e levando a lesões renais. Ratos Munich-Wistar recémnascidos foram divididos em 2 grupos: Controle, sem qualquer tratamento; e PDTCLact, recebendo PDTC ( $280 \mathrm{mg} / \mathrm{Kg} / \mathrm{dia})$ na água do bebedouro do 0 aos 20 dias após o nascimento. Após 10 semanas de vida, 120 ratos machos submetidos à Uninefrectomia e foram estudados em dois protocolos. No protocolo 1, os ratos machos foram subdivididos em: $\mathbf{U N x}+\mathbf{N S}$, ratos Controle recebendo dieta padrão (NS); PDTCLact+UNx+NS, ratos PDTCLact recebendo NS; UNx+SS, ratos Controle recebendo SS; PDTCLact+UNx+SS, ratos PDTCLact recebendo SS. Após 12 semanas, os animais do Grupo UNx+SS apresentaram hipertensão, aumento da albuminúria e lesões renais moderadas. Nos animais do grupo PDTCLact+UNx+SS a hipertensão, esclerose glomerular e a deposição de Colágeno-1 intersticial apresentaram um aumentado exacerbado, juntamente com lesões arteriolares do tipo "casca de cebola", estresse oxidativo, ativação do NF-kB, intenso infiltrado de macrófagos, linfócitos e aumento de células positivas para Angiotensina II, mesmo com a renina plasmática reduzida. Para investigar o papel do sistema renina-angiotensina neste modelo, no protocolo 2 ,

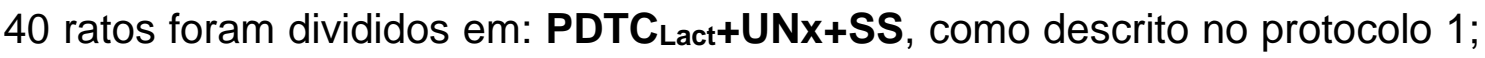
PDTC Lact+UNx+SS+L, ratos tratados com Losartan $(50 \mathrm{mg} / \mathrm{kg})$ na água do bebedouro. O tratamento com Losartan foi capaz de atenuar as lesões glomerulares e a inflamação renal. Esses resultados indicam que a integridade do sistema NF-kB é fundamental para o desenvolvimento adequado do rim e a manutenção da homeostase do sódio na fase adulta. Paradoxalmente, esse mesmo sistema contribui para o desenvolvimento da lesão renal quando a disfunção renal causada por sua inibição durante a nefrogênese é desmascarada por UNx associada ao SS.

Descritores: NF-kappa B; hipertensão; rim; nefropatias; doença renal crônica; inflamação. 


\begin{abstract}
Ávila VF. Salt overload aggravates hypertension and promotes severe renal injury in rats subjected to NF-KB inhibition during nephrogenesis [thesis]. São Paulo: "Faculdade de Medicina, Universidade de São Paulo"; 2018.
\end{abstract}

Recently we described that rats treated with the NF-KB inhibitor pyrrolidine dithiocarbamate (PDTC) during lactation develop high blood pressure hypertensive in adult life, without apparent functional or structural damage to the kidneys, thus providing a new model of essential hypertension. In the present study, we investigated whether uninephrectomy (UNx) associated with saline overload would unveil a possible renal dysfunction, thus aggravating arterial hypertension and leading to hemodynamically mediated renal injury. MunichWistar rat pups were divided into 2 groups: Control, receiving no treatment; and PDTCLact, receiving PDTC ( $280 \mathrm{mg} / \mathrm{kg} /$ day) in the drinking water from 0 to 20 days after birth. At 10 weeks of age, 120 male rats underwent uninephrectomy and were studied in two protocols. In Protocol 1, rats were subdivided into: UNx+NS, control rats receiving normal salt (NS) diet; PDTC Lact+UNx+NS, PDTCLact rats receiving NS; UNx+HS, control rats receiving high-salt $(\mathrm{HS})$ diet; PDTC Lact+UNx+HS, PDTCLact rats receiving HS. After 12 weeks, the UNx+HS animals were moderately hypertensive and exhibited mild albuminuria and renal injury. By contrast, arterial hypertension, glomerulosclerosis and cortical collagen-1 deposition were exacerbated in the PDTC $\mathrm{Lact}_{+} \mathrm{UNx}+\mathrm{HS}$ group, along with "onion skin" arteriolar lesions, evidence of oxidative stress, NF-kB activation and intense infiltration by macrophages, lymphocytes and angiotensin II-positive cells, even though circulating renin was depressed. To investigate the role of the renin-angiotensin system in this setting, 40 rats were divided into:

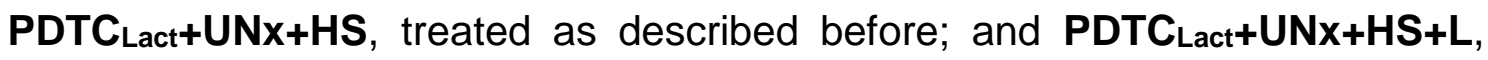
receiving in addition Losartan, $50 \mathrm{mg} / \mathrm{kg}$ in drinking water. Losartan treatment strongly atenuated glomerular injury and renal inflammation. The NF-kB system is essential for the kidneys to develop properly and maintain sodium homeostasis in adult life. Paradoxically, this same system contributes to renal injury when renal dysfunction caused by its inhibition during nephrogenesis is unmasked by UNx associated to HS.

Descriptors: NF-kappa B; hypertension; kidney; nephropathy; chronic kidney disease; inflammation. 


\section{INTRODUÇÃO}

No Brasil, a Sociedade Brasileira de Nefrologia constatou que cerca de 130.000 pacientes necessitam da hemodiálise para sobreviver (1). Dentre esses pacientes o principal diagnóstico de base foi a Hipertensão Arterial. Diante desses fatos, compreender os mecanismos envolvidos na progressão da Hipertensão Arterial na Doença Renal Crônica é essencial para prevenir a porcentagem de pacientes que evoluem para a perda completa da função renal.

A DRC é caracterizada por uma perda progressiva da função renal, atrofia tubular, inflamação e desenvolvimento de fibrose tecidual (2). Muitos são os mecanismos que participam da patogênese da DRC e a associação com a Hipertensão Arterial é muito evidente em modelos experimentais. Em ratos submetidos à nefrectomia de 5/6 (Nx), um dos modelos mais utilizados para estudo das nefropatias progressivas, pode-se observar o desenvolvimento de proteinúria, glomeruloesclerose e fibrose intersticial, associado com hipertensão sistêmica e glomerular $(3,4)$. Neste modelo ocorrem alterações hemodinâmicas nos néfrons remanescentes, como a elevação da pressão hidráulica, e essa agressão mecânica aos glomérulos é seguida da hipertrofia do tufo glormerular, expansão da matriz mesangial, lesões epiteliais e perda de podócitos, resultando em perda de função renal (3).

Fatores inflamatórios também têm papel fundamental na progressão da DRC. A infiltração de células inflamatórias, como os macrófagos e linfócitos, nos glomérulos e interstício renal, contribui para o acúmulo de matriz extracelular e o desenvolvimento de fibrose intersticial $(5,6)$. 


\subsection{Angiotensina II (All) e DRC}

O sistema renina-angiotensina-aldosterona (SRAA), além do seu clássico papel na conservação de sódio e na manutenção da pressão arterial, está diretamente envolvido na patogênese da Hipertensão Arterial e da DRC. Os efeitos biológicos da Angiotensina II (All) mais estudados em animais adultos são os mediados pelo receptor AT1, tais como a vasoconstrição que leva à hipertensão sistêmica e glomerular e a conservação de sódio, por ação direta nos túbulos renais ou via aldosterona. Além desses efeitos, a All está envolvida também nas várias fases do processo inflamatório, regulando a expressão de substâncias bioativas como fatores de crescimento (7-9), citocinas $(6,7,10)$, moléculas de adesão $(11,12)$ e na proliferação de linfócitos (13). Corroborando esses dados, a inibição do SRAA atenua a proliferação de macrófagos e miofibroblastos $(10,14,15)$, diminuem a expressão de fatores de crescimento (16) e das moléculas de adesão $(9,12,17)$. Em todos esses estudos citados acima a diminuição das alterações hemodinâmicas e/ou do processo inflamatório correlacionou com a prevenção do desenvolvimento da glomeruloesclerose (1822). Dados de literatura indicam a participação da All no processo inflamatório da DRC através da ativação de diversas vias de sinalização, tais como a mobilização de cálcio e ativação de proteínas quinases (23), activator protein-1 (AP-1) e fator nuclear kappa B (NF-kB) (10, 24-27). O NF-kB é um fator nuclear de transcrição que regula a expressão de genes essenciais à resposta imune e inflamação. A administração de Losartan, um antagonista do receptor AT1, inibe a ativação de NF-kB e a expressão de MCP-1, moléculas de adesão e citocinas, sugerindo que os genes pró-inflamatórios são regulados também pelo receptor AT1 (28-31). 


\subsection{NF-kB e DRC}

O sistema NF-kB foi inicialmente identificado em linfócitos B e é composto de heterodímeros estáveis, sendo o mais estudado os formados pelas subunidades p50/p65 ligadas a uma subunidade inibidora lkBa (32). O NF-kB se encontra na sua forma inativa no citoplasma, e a ativação desse complexo depende da fosforilação e degradação da subunidade IkBa, uma proteína inibitória ligada aos heterodímeros, e migração do heterodímero p50/p65 para o núcleo, onde promove a síntese de moléculas inflamatórias (32). O sistema NFKB pode ser ativado em diversos tipos de células, através de estímulos fisiológicos e patológicos, tais como citocinas, agentes mitogênicos, vírus, estresses mecânicos ou oxidativos $(10,13)$. A ativação do sistema NF-kB pode ocorrer também através dos toll-like receptors (TLRs), que constituem uma numerosa família de receptores celulares. Os TLRs são ligados a proteínas de membrana ou intracelulares, como o MyD88, promovendo, quando ocupados, a estimulação do sistema NF-KB e, consequentemente, a produção de uma série de mediadores que amplificam a intensidade da resposta inflamatória, atraindo ao local células sanguíneas que, por sua vez, sintetizam novos mediadores, em um típico processo de realimentação positiva $(33,34)$. Uma vez ativado, o sistema NF-kB controla a expressão gênica de vários agentes pró-inflamatórios, aumentando a expressão de monocyte chemoattractant protein-1 (MCP-1) (10, 35), ciclooxigenase-2 (COX-2) $(36,37)$, citocinas como IL-6 e IL-1 $\beta$ (38), moléculas de adesão $(38,39)$, linfócito T, iNOS (37-39) e endotelina (37).

O sistema NF-kB participa das principais vias de sinalização intracelular envolvidas nas doenças inflamatórias crônicas (40) e a sua ativação pode ser 
um indicador da progressão da doença renal. O aumento da ativação de NF-kB foi observada em pacientes com glomerulopatia de lesões mínimas, nefropatia membranosa, nefropatia da IgA (41), síndrome nefrótica (42) e nefropatia diabética $(27,43)$. No modelo de redução da massa renal de $5 / 6(\mathrm{Nx})$, o aumento na atividade de NF-kB foi observado na área intersticial, glomerular e vascular (44, 45). O sistema NF-kB pode ser bloqueado através da prevenção da degradação do lkBa, que é possível com o tratamento das células com proteases inibidoras ou de um antioxidante (32), como o pyrrolidinedithiocarbamate (PDTC) que é um potente antioxidante e inibidor do NF-kB $(22,46)$. A administração do PDTC inibe a indução de VCAM-1 (47), expressão de MCP-1, expressão de iNOS e proliferação celular (38). Demonstramos anteriormente em nosso laboratório que ratos $\mathrm{Nx}$ tratados com PDTC apresentaram redução na expressão da subunidade p65 de NF-kB no tecido renal e estava associada à normalização da na pressão arterial sistêmica, redução na albuminúria, inflamação renal, lesões glomerulares e intersticiais (45).

\subsection{Angiotensina II e NF-kB na Nefrogênese}

Além dos seus efeitos pró-inflamatórios, a All tem papel fundamental na formação dos rins. Sabe-se que em ratos, durante o período neonatal, a atividade da ECA e a própria All estão aumentadas no tecido renal, assim como

a dos receptores AT-1 e AT-2. Vários estudos demonstraram que a administração de inibidores SRAA durante esta fase acarreta alterações estruturais irreversíveis, que se reflete em grave limitação da função renal na fase adulta $(48,49)$. Em roedores, a nefrogênese se completa durante o período de lactação, que corresponde às 3 primeiras semanas de vida extra-uterina (48). 
Um estudo realizado anteriormente em nosso laboratório (49) mostrara que a administração de Losartan (antagonista do receptor AT1) durante o período de lactação resultou em alterações estruturais irreversíveis na fase adulta. A associação de redução no número de néfrons, o aumento na permeabilidade glomerular, a hipertensão glomerular e a heterogeneidade quanto ao volume glomerular resultaram em lesões glomerulares e intersticiais associadas à inflamação renal.

Assim como a All, provavelmente o NF-kB também tem um papel importante no desenvolvimento embrionário (50). Como foi descrito anteriormente, a expressão do gene c-Rel do NF-kB está associada ao desenvolvimento das ramificações que originam os membros dos vertebrados na fase embrionária $(51,52)$. Além disso, sabe-se que o modelo experimental de camundongos knockout para um gene p65 do NF-kB leva a um fenótipo embriogênico letal associado com apoptose celular maciça no fígado, enquanto que camundongos knockout para o gene p50 não apresentam nenhum tipo de anormalidade no desenvolvimento. Apesar disso, pouco se conhece sobre a ação do NF-kB durante a nefrogênese. Tendo em vista que o NF-kB age como um fator de transcrição para o desenvolvimento do sistema imune, da regulação do ciclo celular e da apoptose e intermedeia várias ações da All, é razoável supor que a via do NF-kB possa mediar também os efeitos da All sobre a nefrogênese.

No nosso laboratório, desenvolvemos um estudo em que o sistema NF-kB foi bloqueado durante a fase final da nefrogênese (53). Vinte e quatro horas após o nascimento, os ratos receberam PDTC (via leite materno) durante 20 dias, inibindo a participação do NF-kB na fase final da nefrogênese. Na fase adulta, os animais que receberam PDTC durante a lactação tornaram-se hipertensos 
sem a presença de alterações morfológicas visíveis nos tecidos renais. Além disso, os resultados do estudo da expressão gênica do SRAA mostraram um discreto aumento na expressão de renina no tecido renal, apresentando normalidade nos outros componentes desse sistema. Constatou-se, no entanto a presença de fibrose no tecido cardíaco, evidenciando uma alteração na morfologia cardíaca em consequência da hipertensão sistêmica nesses animais. Uma das possíveis hipóteses para a presença de hipertensão arterial nesses animais é uma alteração túbulo-intersticial, modificando assim a capacidade de excreção de eletrólitos. Esses resultados indicam que o sistema NF-KB também participa da organogênese, não de uma maneira intensa como All, e seu bloqueio promove hipertensão arterial e fibrose cardíaca, mas sem promover lesão renal grave.

Mas seria possível promover alterações morfológicas significativas neste modelo? Estudos anteriores mostraram que em modelos como Diabetes Mellitus a redução da massa renal acelerou o aparecimento de lesões renais (54), e no modelo L-Name (55) a sobrecarga salina na dieta também foi capaz de acelerar as lesões renais. 


\section{OBJETIVOS}

O objetivo deste estudo é investigar se no modelo de hipertensão decorrente da inibição do sistema NF-kB durante a nefrogênese:

- A associação da uninefrectomia com a sobrecarga salina na dieta promove o aparecimento de lesões renais.

- Uma vez evidenciadas as lesões renais neste modelo, avaliar os mecanismos celulares envolvidos na sua patogênese. 


\section{MATERIAIS E MÉTODOS}

Foram utilizados ratos da cepa Munich-Wistar obtidos de uma colônia dessa linhagem de ratos estabelecida no biotério do Laboratório de Fisiopatologia Renal. Os animais foram mantidos a uma temperatura $\left(22 \pm 1^{\circ} \mathrm{C}\right) \mathrm{e}$ umidade relativa do ar (60 $\pm 5 \%)$ controlada e num ciclo de claro/escuro de 12/12 horas. Os procedimentos utilizados nesse estudo seguiram as normas da Comissão de Ética para Análise de Projetos de Pesquisa (CAPPesq, protocolo de pesquisa $N^{\circ}$ 369/11) da Faculdade de Medicina da Universidade de São Paulo.

\subsection{Obtencão do modelo experimental}

As ratas grávidas foram mantidas em gaiolas individuais de polipropileno e receberam dieta padrão contendo $0,5 \%$ de $\mathrm{Na}^{+}$e $22 \%$ de proteína (Nuvital, Curitiba, Brazil) e livre acesso à água. Um dia após o nascimento, 6 filhotes (machos e fêmeas) foram mantidos em cada ninhada e as mães receberam o inibidor de NF-kB, o Pyrrolidine Dithiocarbamate (PDTC), dissolvido na água do bebedouro na dose $70 \mathrm{mg} / \mathrm{rata}$ (equivalente a $280 \mathrm{mg} / \mathrm{kg} / \mathrm{dia}$ ). Os filhotes receberam o PDTC via leite materno, como foi demonstrado em estudos com o bloqueio do SRA (49). Após 3 semanas, a administração do PDTC foi interrompida e os filhotes foram mantidos com a mãe até o desmame (25 dias de vida). Também foram acompanhadas mães com suas respectivas ninhadas que não receberam nenhum tratamento durante a fase de lactação (grupo Controle). Após o desmame, os filhotes machos foram identificados e pesados semanalmente até completarem 10 semanas de vida. 
Após 10 semanas de vida, todos os animais foram anestesiados (i.m) com uma solução de ketamina (Cristália, $50 \mathrm{mg} / \mathrm{kg}$ ) e rompun (Bayer, $10 \mathrm{mg} / \mathrm{kg}$ ) e submetidos à cirurgia de UNx. Antes do procedimento cirúrgico, os animais receberam o antibiótico enrofloxacino $(1,25 \mathrm{mg} / \mathrm{Kg})$. Após assepsia, os animais foram submetidos à laparotomia mediana e então foi removido o rim direito, obtendo assim o modelo de uninefrectomia (UNx). Após a cirurgia, os animais foram mantidos em gaiolas aquecidas por 24 horas e medicados com o analgésico cloridrato de tramadol $(10 \mathrm{mg} / \mathrm{kg})$.

Ao completarem 12 semanas de vida o peso corpóreo (PE) foi avaliado e os animais foram colocados em gaiolas metabólicas para a determinação da albuminúria de 24 horas (ALB). Posteriormente, as medidas de pressão sistólica caudal (PC) foram realizadas através do método opto-eletrônico (BP 2000 Blood Pressure Analysis System, Visitech Systems, EUA). Os animais foram então subdivididos nos grupos experimentais e acompanhados até as 24 semanas de vida.

Neste estudo utilizamos ratos cujas mães receberam água no bebedouro (Controle) e os que receberam PDTC durante a lactação (PDTC Lact) que foram avaliados em dois protocolos experimentais: No protocolo 1, nós verificamos as alterações renais em animais submetidos a Uninefrectomia (UNx) associada à sobrecarga salina ( $3,2 \%$ de $\mathrm{NaCl}$ na ração e $0,5 \%$ de $\mathrm{NaCl}$ na água do bebedouro, SS); No protocolo 2, os animais PDTCLact +UNx+SS foram tratados com Losartan (bloquedor do receptor AT1 da Angiotensina II) na dose de 50 $\mathrm{mg} / \mathrm{Kg}$. 


\section{Protocolo 1}

UNx+NS: Dezenove ratos Controle foram submetidos a UNx ao completarem 10 semanas de vida. Após a cirurgia, os animais foram mantidos com dieta padrão (NS) durante 12 semanas (24 semanas de vida).

PDTC Lact+UNx+NS: Dezenove ratos PDTC Lact foram submetidos a UNx ao completarem 10 semanas de vida. Após a cirurgia, os animais foram mantidos com dieta NS durante 12 semanas (24 semanas de vida).

UNX+SS: Vinte e um ratos Controle foram submetidos a UNx ao completarem 10 semanas de vida. Após a cirurgia, os animais foram mantidos com sobrecarga salina (SS) na dieta durante 12 semanas (24 semanas de vida).

PDTC Lact+UNx+SS: Vinte e um ratos PDTC Lact foram submetidos a UNx ao completarem 10 semanas de vida. Após a cirurgia, os animais foram mantidos com dieta SS durante 12 semanas (24 semanas de vida).

\section{Protocolo 2}

Uma vez que no protocolo 1 observamos instalação da DRC, o protocolo 2 tem o objetivo de investigar o papel da All no mecanismo de lesão renal neste modelo. Os animais foram divididos nos seguintes grupos experimentais:

PDTC Lact+UNX+SS: Dezenove ratos PDTC Lact foram submetidos a UNx ao completarem 10 semanas de vida. Após a cirurgia, os animais foram mantidos com dieta SS durante 12 semanas (24 semanas de vida).

> PDTC Lact+UNx+SS+L: Vinte e um ratos PDTCLact foram submetidos a UNx ao completarem 10 semanas de vida. Após a cirurgia, os animais foram mantidos com dieta SS e Losartan (50 mg/Kg/dia) durante 12 semanas (24 semanas de vida). 
Com 24 semanas de vida, os animais foram pesados e colocados em gaiolas metabólicas para a determinação da albuminúria de $24 \mathrm{~h}$ e da pressão caudal. Uma amostra de sangue foi coletada para dosagem de atividade plasmática de renina. Após esse procedimento os animais foram anestesiados (i.m.) com a solução ketamina (Cristália, $50 \mathrm{mg} / \mathrm{kg}$ ) e rompun (Bayer, $10 \mathrm{mg} / \mathrm{kg}$ ) e o sangue coletado da aorta abdominal para as análises bioquímicas. De onze a treze animais de cada grupo experimental tiveram o tecido renal perfundido, inicialmente com solução fisiológica e em seguida com uma solução DubosqcBrazil, para a fixação in situ do tecido. Após esse procedimento, o tecido renal foi pesado e preparado para exames histológicos e imuno-histoquímicos. Adicionalmente, o tecido renal de oito animais de cada grupo foi perfundido somente com solução fisiológica. Em seguida, o tecido renal foi removido rapidamente e congelado em nitrogênio líquido para subsequente extração de proteína e RNA.

\subsection{Estudos bioquímicos}

Albuminúria de 24 horas $(A L B)$ - A presença de albumina na urina foi avaliada pela técnica de imunodifusão radial, empregando um anticorpo específico (anti-albumina de rato, MPBiomedicals LLC, EUA) (56).

Clearance de creatinina (Cl Cr) - A concentração de creatinina foi avaliada no soro e na urina através da análise colorimétrica, utilizando kit comercial disponível (Labtest Diagnóstica S.A.).

Sódio $\left(\mathrm{Na}^{+}\right)$e potássio $\left(K^{+}\right)$plasmáticos - A determinação da concentração do sódio e do potássio no sangue total foi realizada a partir de coleta sanguínea 
da aorta abdominal e dosada através do analisador de eletrólitos 9140 (AVL Medical Instruments).

Atividade plasmática de renina $(A P R)$ - Com o intuito de evitar a interferência da anestesia na quantificação da APR, a coleta de sangue foi realizada através da veia caudal em animais acordados. A determinação da APR foi realizada através de kit de Radioimunoensaio (GENESE - Produtos Farmacêuticos e Diagnósticos)

\subsection{Estudo histológico do tecido renal}

Esclerose glomerular (EG) - A EG foi avaliada em tecidos renais submetidos à reação do ácido periódico de Shiff (PAS). A quantificação de EG foi realizada através da contagem do número de glomérulos com esclerose (\%EG), independente da extensão da lesão esclerose glomerular. Para essa avaliação foram analisados 200 glomérulos por corte, sob aumento de 400x (57).

Lesão Arteriolar (LA). - A LA foi avaliada em tecidos renais submetidos à reação do ácido periódico de Shiff (PAS). A quantificação de LA foi realizada através da contagem do número de arteríolas com proliferação das células miointimais (\%LA), independente da extensão da lesão arteriolar. Para essa avaliação foram analisadas 30 arteríolas por corte, sob aumento de 400x (57).

Expansão intersticial (INT) - A expansão intersticial foi avaliada em tecidos renais submetidos à reação de Tricrômio de Masson. A quantificação de INT foi realizada por um método de contagem de pontos no compartimento intersticial da área cortical do rim (\%INT). Para essa avaliação foram analisadas 25 áreas consecutivas, num aumento final de 200x com uma ocular graticulada de 144 pontos (58). 


\subsection{Quantificação das interleucinas (ELISA)}

$\underline{M C P-1}$ - Para a detecção da quantidade de Monocyte Chemoattractant Protein-1 (MCP-1) no tecido renal foi utilizado o método Elisa Sanduíche, utilizando kit comercial (R\&D systems). O protocolo da técnica e as concentrações utilizadas seguiram as recomendações do fabricante. Para cada amostra, foram utilizados $100 \mu \mathrm{l}$ de proteína do extrato tecidual.

\subsection{Estudo imuno-histoquímico do tecido renal}

Os estudos imuno-histoquímicos foram realizados em cortes histológicos de $5 \mu \mathrm{m}$ de espessura, montados sobre lâminas previamente silanizadas. Essas lâminas foram desparafinizadas e reidratadas através de aquecimento (em estufa a $60^{\circ} \mathrm{C}$ durante 30 minutos) seguido por uma série de banhos de xilol e etanol em concentrações decrescentes. Em seguida, as lâminas foram mantidas em água destilada por no mínimo 5 minutos. Para a recuperação antigênica, os tecidos foram submetidos a calor úmido (aproximadamente $95^{\circ} \mathrm{C}$ ) e em solução de ácido cítrico $10 \mathrm{mM}$ tamponado $(\mathrm{pH}$ 6,0) por um período de 30 minutos. Para todos os marcadores utilizamos a solução salina tris-tamponada TBS $(0,05 \mathrm{M}$ de Tris e $0,15 \mathrm{M}$ de cloreto de sódio $\mathrm{pH} 7,6$ ) como tampão de lavagem. Todas as incubações foram realizadas em câmara úmida a fim de evitar o ressecamento dos tecidos renais.

Os métodos utilizados para o estudo imuno-histoquímico foram: o APAAP (Fosfatase Alcalina Anti-Fosfatase Alcalina), a técnica da Estreptavidina Fosfatase Alcalina e a técnica da Peroxidase. Os anticorpos utilizados para caracterização do processo inflamatório foram: Anti-ED1 (monócitos e 
macrófagos), Anti-colágeno tipo I (colágeno tipo 1), Anti-All (angiotensina II) e anti-CD3 (Linfócitos T).

Infiltração de Macrófagos (M申) - A identificação de células positivas para macrófagos foi realizada pelo método de APAAP (Fosfatase Alcalina AntiFosfatase Alcalina). Após a desparafinização e recuperação antigênica, os tecidos foram submetidos ao bloqueio de marcação inespecífica com soro não imune de coelho (Dako, Carpinteria, CA, EUA), em concentração 1:20 por 30 minutos. Os tecidos foram incubados com o anticorpo primário desenvolvido em camundongo anti-ED-1 (Serotec, MCA341R Oxford, Reino Unido) na diluição $1: 200$, à temperatura de $3-8^{\circ} \mathrm{C}$ durante um período de 18 horas. Após a retirada do excesso de anticorpo primário, os cortes foram lavados com TBS e incubados com o anticorpo secundário anti-camundongo desenvolvido em coelho - RAM (Dako, Carpinteria, CA, EUA) na diluição 1:50 à temperatura ambiente durante 30 minutos. Após nova lavagem em TBS, os cortes foram incubados com o Complexo APAAP na diluição 1:70 por 30 minutos. Ao final desse procedimento, o tecido estava pronto para a revelação em tempo variável com substrato cromogênico Permanent-Red. As células positivas para o epítopo ED-1 foram visualizadas devido à precipitação do produto da reação da fosfatase alcalina do Complexo e do Permanent-Red presente no substrato cromogênico. A contracoloração foi realizada com hematoxilina de Mayer (Hemalaum-Merck) durante 1 minuto. Os cortes foram colocados entre a lâmina e a lamínula com meio de montagem aquoso de Mayer (Glycergel) e foram em seguida devidamente etiquetados. A quantificação de macrófagos foi realizada pela contagem de células marcadas no córtex renal com aumento de 400X. Foram examinados 25 campos microscópicos para cada seção, correspondendo a uma 
área de $0,08 \mathrm{~mm}^{2}$. Os resultados foram expressos em células por milímetro quadrado (cél/mm²).

Identificação de Colágeno I (COL) - A identificação de COL intersticial foi realizada utilizando o método da Peroxidase. Após a desparafinização e recuperação antigênica procedeu-se o bloqueio da peroxidase endógena com solução de peróxido de hidrogênio por 30 minutos. Após serem lavadas com tampão TBS, os cortes foram incubados com soro não imune de cavalo na diluição de 1:50 para bloqueio de marcação inespecífica por 30 minutos. Retirouse o excesso de soro e os tecidos renais foram incubados com o anticorpo primário anti-colageno tipo I (Abcam®, Cambridge, UK) diluído na proporção de 1:200 em solução de BSA a $1 \%$ em TBS, à temperatura de $3-8^{\circ} \mathrm{C}$ durante um período de 18 horas. Após lavagem em TBS, os cortes foram incubados com $80 \mu$ de Envision Flex HRP (Dako, Carpinteria, CA, EUA), durante 30 minutos. O substrato cromogênico DAB (Dako, Carpinteria, CA, EUA) foi preparado na proporção de 1:20 em substrato. A contracoloração foi realizada com Hematoxilina de Mayer 100\% (Hemalaum-Merck) durante 2 minutos. Os cortes foram colocados entre a lâmina e a lamínula com meio de montagem aquoso de Mayer (Glycergel) e foram em seguida devidamente etiquetados. A Fração do córtex renal ocupada por colágeno I foi quantificada por um método de contagem de pontos em 25 campos microscópicos consecutivos, num aumento final de 200x com uma ocular graticulada de 144 pontos [58].

Identificação de células positivas para All - Para avaliação de células positivas para All foi empregada a técnica de Estreptavidina-Biotina-Fosfatase Alcalina. Após a desparafinização e exposição dos epítopos, os tecidos foram submetidos ao bloqueio da biotina endógena através da incubação com solução 
de bloqueio de Avidina e Biotina (Dako, Carpinteria, CA, EUA) por 15 minutos cada. Depois, foram incubados com soro não imune de cavalo (Vector Lab, Burlingame, EUA) na concentração de 1:50 diluído em leite a 5\% em TBS por 30 minutos. Em seguida, os cortes foram incubados por 24 horas com o anticorpo primário anti-All (Península Laboratories, San Carlos, CA), diluído em BSA 1\% na proporção de 1:400. No dia seguinte, os cortes foram incubados com anticorpo secundário anti-coelho biotinilado (Vector BA-1000), diluído em BSA 1\% na proporção de 1:1000, durante 45 minutos. Em seguida, os cortes foram incubados durante 30 minutos com o Complexo Streptavidina-AP (Vector Vectastain ABC-AP \#AK5000) e revelados com substrato cromogênico Fast Red com tempo variável. A quantificação das células intersticiais positivas para All foi realizada através da contagem de células marcadas no córtex renal, ao microscópio com aumento de 400x. Foram analisados 25 campos para cada lâmina. Os resultados foram apresentados como células positivas por milímetro quadrado (cel/ $\left./ \mathrm{mm}^{2}\right)$.

Identificação de Linfócitos $T(L y)$ - Para avaliação da expressão de Ly foi empregada a técnica da Estreptavidina-Biotina-Fosfatase Alcalina. Após a desparafinização e exposição dos epítopos, os tecidos foram submetidos ao bloqueio da biotina endógena através da incubação com solução de bloqueio de Avidina e Biotina (Dako \#X0590) por 15 minutos cada. Depois, foram incubados com soro não imune de cavalo (Vector \#S-2000) na concentração de 1:50 diluído em solução de BSA 1\% por 30 minutos. Em seguida, os cortes foram incubados por 24 horas com o anticorpo primário anti-CD3 (Dako \#M7254) diluído em BSA $1 \%$ na proporção de 1:100. No dia seguinte, os cortes foram incubados com os anticorpos secundários anti-camundongo biotinilado (Vector BA-2001) diluído 
em BSA 1\% na proporção de 1:200 durante 45 minutos. Depois disso, os cortes foram incubados durante 30 minutos com o Complexo Streptavidina-AP (Vector Vectastain ABC-AP \#AK5000). Ao final desse procedimento, o tecido estava pronto para a revelação em tempo variável com substrato cromogênico Fast Red. As células positivas para o epítopo CD3 foram visualizadas devido à precipitação do produto da reação da fosfatase alcalina do Complexo e do Fast Red presente no substrato cromogênico. A contracoloração foi realizada com hematoxilina de Mayer (Hemalaum-Merck) durante 1 minuto. Os cortes foram colocados entre a lâmina e a lamínula com meio de montagem aquoso de Mayer (Glycergel) e foram em seguida devidamente etiquetados. A quantificação de linfócitos foi realizada pela contagem de células marcadas no córtex renal com aumento de 400X. Foram examinados 25 campos microscópicos para cada seção, correspondendo a uma área de $0,08 \mathrm{~mm}^{2}$. Os resultados foram expressos em células por milímetro quadrado (céls $/ \mathrm{mm}^{2}$ ).

\subsection{Análise do conteúdo protéico do tecido renal (Western Blot)}

Extração e quantificação de proteínas teciduais - Amostras de rim com peso de 100 a $200 \mathrm{mg}$ foram colocados em tubos de polipropileno reforçado, contendo microesferas de cerâmica (OMNI 19-628), tampão RIPA e inibidores de proteases e fosfatases (Complete-EDTA e PhosSTOP, Roche ${ }^{\circledR}$ ). Essa mistura foi homogeneizado no aparelho OMNI BEAD RUPTOR 24. O teor proteico foi determinado através do kit comercial (Pierce BCA Protein Assay Kit, Thermo Scientific $\left.{ }^{\circledR}\right)$, seguindo as instruções do fabricante. Para a corrida eletroforética, foram utilizados $100 \mu \mathrm{g}$ de proteína do extrato tecidual diluído em Tampão de Amostra (Laemmli Sample Buffer - BIO RAD). 
Conteúdo proteico de TLR4 - A análise de TLR4 nos tecidos renais foi realizada em gel de poliacrilamida 10\% (SDS-PAGE), que se completou em aproximadamente 1 hora e 30 minutos, a 120 Volts. Em seguida, o gel foi transferido (transferência semi-úmida) para uma membrana de nitrocelulose, durante 45 minutos a 20 Volts. Para a confirmação da transferência, a membrana foi corada com Solução de Ponceau (Sigma-Aldrich ${ }^{\circledR}$ ). Posteriormente, a membrana foi lavada 3 vezes com tampão TBSt e o bloqueio de marcação inespecífica foi realizado com albumina sérica bovina (BSA) 5\% diluída em tampão TBS, por 2 horas em temperatura ambiente, sob leve agitação. Após o bloqueio, a membrana foi incubada com o anticorpo primário anti-TLR4 (Santa Cruz Biotechnology $\left.{ }^{\circledR}\right)$, diluído em BSA 1\%, na proporção 1:250, por 18 horas, à temperatura de $4^{\circ} \mathrm{C}$. Em seguida, a membrana foi lavada três vezes com solução de TBSt e incubada com o anticorpo secundário (Anti-rabbit-HRP: 1:5000, Sigma-Aldrich ${ }^{\circledR}$ ), por 2 horas sob agitação, seguindo-se de nova lavagem com TBSt e revelação.

Atividade de NF-KB - Para a detecção do conteúdo proteico nuclear de p65 fosforilado (NF-KB ativo) por Western blot no tecido renal, foi realizada primeiramente a separação da fração nuclear e citoplasmática das células do tecido renal. Para isso, fragmentos de $100 \mathrm{mg}$ de tecido foram homogeneizados com auxílio de um homogeneizador apropriado (Dounce Tissue Grinders, Kimble Chase) em $1 \mathrm{~mL}$ de Solução de Lise (20mM HEPES pH7,4, 10mM KCl, 1,5mM $\mathrm{MgCl}_{2}, 0,25 \mathrm{M}$ Sacarose, 10\% Glicerol, 0,5\% NP-40), com 1 comprimido de inibidor de fosfatase e 1 de inibidor de protease (Roche $\left.{ }^{\circledR}\right)$. O homogenato foi transferido para um tubo e centrifugado $\left(10^{\prime}, 4^{\circ} \mathrm{C}, 1000 \mathrm{G}\right)$. Após a retirada do sobrenadante (fração citoplasmática), o pellet (fração nuclear) foi lavado 2 vezes 
através de suspensão em $1 \mathrm{~mL}$ de Solução de Lise e posterior centrifugação (10', $\left.4^{\circ} \mathrm{C}, 1000 \mathrm{G}\right)$ e descarte do sobrenadante. Após as lavagens, o pellet foi homogeneizado em 200 $\mu \mathrm{L}$ de Tampão de Amostra (0,125M Tris-HCl pH6,8, 10\% $2 \beta$-Mercaptoetanol, 4\% SDS, $10 \%$ Sacarose, 0,2\% Bromophenol-blue), seguido por centrifugação $\left(10^{\prime}, 4^{\circ} \mathrm{C}, 1500 \mathrm{G}\right)$. O pellet foi descartado e o sobrenadante (fração nuclear) foi transferido para um tubo e armazenado a $-80^{\circ} \mathrm{C}$. Para a corrida eletroforética foram utilizados $30 \mu \mathrm{L}$ do extrato tecidual diluído em Tampão de Amostra. A corrida foi realizada em gel de poliacrilamida $12 \%$ e se completou em aproximadamente 1 hora e 30 minutos, a 120 Volts. Em seguida, o gel foi transferido (transferência semi-úmida) para uma membrana de nitrocelulose, durante 45 minutos a 20 Volts, e foi feita a confirmação de transferência. Após a lavagem da membrana, foi realizada o bloqueio de marcação inespecífica e a incubação da membrana com o anticorpo primário anti-p65 fosforilada (Santa Cruz Biotechnology ${ }^{\circledR}$ ), diluído em BSA 1\%, na proporção 1:100, por 18 horas, à temperatura de $4^{\circ} \mathrm{C}$. Em seguida, a membrana foi lavada três vezes com solução de TBSt e incubada com o anticorpo secundário (Anti-rabbit-HRP: 1:5000, Sigma-Aldrich ${ }^{\circledR}$ ), por 2 horas sob agitação, seguindo-se de nova lavagem com TBSt e revelação.

Conteúdo proteico de IL-6 - A análise de interleucina 6 (IL-6) nos tecidos renais foi realizada em gel de poliacrilamida $15 \%$ (SDS-PAGE) e se completou em aproximadamente 1 hora e 30 minutos, a 120 Volts. Em seguida, o gel foi transferido (transferência semi-úmida) para uma membrana de nitrocelulose, durante 45 minutos a 20 Volts. Para a confirmação da transferência, a membrana foi corada com Solução de Ponceau (Sigma-Aldrich ${ }^{\circledR}$ ). Posteriormente, a membrana foi lavada 3 vezes com tampão TBSt e o bloqueio de marcação 
inespecífica foi realizado com leite 5\% diluída em tampão TBS, por 2 horas em temperatura ambiente, sob leve agitação. Após o bloqueio, foi realizada a incubação da membrana com o anticorpo primário anti-IL-6 (Abcam ${ }^{\circledR}$ ab\#9324), diluído em BSA $1 \%$, na proporção 1:250, por 18 horas, à temperatura de $4^{\circ} \mathrm{C}$. Em seguida, a membrana foi lavada três vezes com solução de TBSt e incubada com o anticorpo secundário (Anti-mouse-HRP: 1:5000, Sigma-Aldrich ${ }^{\circledR}$ \#A9044), por 2 horas sob agitação, seguindo-se de nova lavagem com TBSt e revelação.

Conteúdo proteico de Heme-oxygenase 1 (HO-1) - A análise de HO-1 nos tecidos renais foi realizada em gel de poliacrilamida 12\% (SDS-PAGE) e se completou em aproximadamente 1 hora e 30 minutos, a 120 Volts. Em seguida, o gel foi transferido (transferência semi-úmida) para uma membrana de nitrocelulose, durante 45 minutos a 20 Volts. Para a confirmação da transferência, a membrana foi corada com Solução de Ponceau (SigmaAldrich ${ }^{\circledR}$. Posteriormente, a membrana foi lavada 3 vezes com tampão TBSt e 0 bloqueio de marcação inespecífica foi realizado com leite $5 \%$ diluída em tampão TBSt, por 2 horas em temperatura ambiente, sob leve agitação. Após o bloqueio, foi realizada a incubação da membrana com o anticorpo primário anti-HO-1 (Abcam \#ab13248), diluído em BSA 1\%, na proporção 1:250, por 18 horas, à temperatura de $4^{\circ} \mathrm{C}$. Em seguida, a membrana foi lavada três vezes com solução de TBSt e incubada com o anticorpo secundário (Anti-rabbit-HRP: 1:5000, Sigma-Aldrich ${ }^{\circledR}$ \#A9044), por 2 horas sob agitação, seguindo-se de nova lavagem com TBSt e revelação.

Conteúdo proteico de "Mitochondrial antioxidant manganese superoxide dismutase" (MnSOD) - Antes de iniciar o ensaio para a quantificação de MnSOD, todas as amostras do tecido renal foram diluídas a fim de obter uma 
concentração de 25ug por amostra. A corrida eletroforética das amostras para análise de MnSOD foi realizada em gel de poliacrilamida 15\% (SDS-PAGE) e se completou em aproximadamente 1 hora e 30 minutos, a 120 Volts. Em seguida, o gel foi transferido (transferência úmida) para uma membrana de nitrocelulose, durante 45 minutos a 20V. Para a confirmação da transferência, a membrana foi corada com Solução de Ponceau (Sigma-Aldrich ${ }^{\circledR}$ ). Posteriormente, a membrana foi lavada 3 vezes com tampão TBSt e o bloqueio de marcação inespecífica foi realizado com leite $5 \%$ diluída em tampão TBS, por 2 horas em temperatura ambiente, sob leve agitação. Após o bloqueio, foi realizada a incubação da membrana com o anticorpo primário anti-MnSOD (Cayman 10011389), diluído em BSA 1\%, na proporção 1:250, por 18 horas, à temperatura de $4^{\circ} \mathrm{C}$. Em seguida, a membrana foi lavada três vezes com solução de TBSt e incubada com o anticorpo secundário (Anti-rabbit-HRP: 1:5000, Sigma-Aldrich ${ }^{\circledR} \#$ A9169), por 2 horas sob agitação, seguindo-se de nova lavagem com TBSt e revelação.

Identificação e quantificação das bandas de Western Blot - A revelação das membranas foi feita por quimioluminescência, utilizando kit comercial (Pierce SuperSignal West Pico Chemiluminescent Substrate, Thermo Scientific $\left.{ }^{\circledR}\right)$, e as imagens foram registradas com aparelho fotodocumentador (UVITEC Cambridge ${ }^{\circledR}$ ). A identificação, a analise e a quantificação das bandas foram realizadas através do software Uvisoft-UvibandMax (Uvitec Cambridge ${ }^{\circledR}$ ). A proteína constitutiva $\beta$-actina (anti- $\beta$-actina, Sigma-Aldrich ${ }^{\circledR}, 1: 5000$ em BSA 1\%) foi utilizada para a normalização dos resultados das proteínas alvo TLR4, IL-6, HO-1, MnSOD. Para a normalização dos resultados da proteína alvo p65 
fosforilada, foi utilizada a proteína constitutiva nuclear histona H2B (anti-histona H2B, Abcam ${ }^{\circledR}, 1: 1000$ em BSA 1\%).

\subsection{Análise estatística}

Os resultados obtidos no estudo foram apresentados como Média \pm Erro Padrão. No protocolo 1 os dados e foram submetidos à análise de variância de dois fatores (ANOVA), com comparações pareadas entre grupos pelo método de Newman-Keuls (59), utilizando o software GraphPad Prism®, versão 4.0. Os dados do protocolo 2 foram submetidos ao teste t student. As correlações foram determinadas através do cálculo do coeficiente de Pearson. O nível de significância estatística foi definido como p<0,05. 


\section{RESULTADOS}

\subsection{Protocolo 1}

A seguir serão apresentados os resultados obtidos ao final das 24 semanas de vida dos animais UNx+NS, PDTCLact+UNx+NS, UNx+SS e PDTCLact+UNx+SS pertencentes ao protocolo 1.

Tabela 1. Parâmetros gerais do protocolo 1

\begin{tabular}{|c|c|c|c|c|}
\hline & $\begin{array}{c}\mathrm{UNx}+\mathrm{NS} \\
\mathrm{N}=11\end{array}$ & $\begin{array}{c}\text { PDTC }_{\text {Lact }+U N x+N S} \\
N=11\end{array}$ & $\begin{array}{c}\mathrm{UNx}+\mathrm{SS} \\
\mathrm{N}=13\end{array}$ & $\begin{array}{c}\text { PDTC }_{\text {Lact }}+\mathrm{UNx}+\mathrm{SS} \\
\mathrm{N}=13\end{array}$ \\
\hline $\mathrm{PE}$ (gramas) & $355 \pm 6$ & $360 \pm 8$ & $364 \pm 8$ & $357 \pm 4$ \\
\hline $\mathrm{Na}^{+}(\mathrm{mEq} / \mathrm{mL})$ & $145 \pm 0,5$ & $143 \pm 0,6$ & $145 \pm 0,6$ & $144 \pm 0,3$ \\
\hline $\mathrm{K}^{+}(\mathrm{mEq} / \mathrm{mL})$ & $4,5 \pm 0,2$ & $4,2 \pm 0,1$ & $4,5 \pm 0,1$ & $4,5 \pm 0,2$ \\
\hline $\mathrm{PC}(\mathrm{mmHg})$ & $144 \pm 2$ & $167 \pm 3^{a}$ & $165 \pm 2^{b}$ & $195 \pm 4^{\mathrm{ab}}$ \\
\hline ALB (mg/24h) & $43 \pm 10$ & $45 \pm 9$ & $130 \pm 18^{b}$ & $167 \pm 32^{b}$ \\
\hline $\mathrm{Cl} \mathrm{Cr}(\mathrm{mL} / \mathrm{min})$ & $1,3 \pm 0,1$ & $1,2 \pm 0,1$ & $1,4 \pm 0,1$ & $1,0 \pm 0,1^{a}$ \\
\hline EG (\%) & $2,1 \pm 0,1$ & $1,2 \pm 0,4$ & $7,1 \pm 1,4^{b}$ & $12,1 \pm 2,2^{\mathrm{ab}}$ \\
\hline LA (\%) & $0 \pm 0$ & $0,6 \pm 0,6$ & $4,4 \pm 1,7$ & $17,5 \pm 5,5^{\mathrm{ab}}$ \\
\hline INT (\% área) & $0,3 \pm 0,2$ & $0,5 \pm 0,1$ & $0,9 \pm 0,5$ & $4,9 \pm 1,4^{\mathrm{ab}}$ \\
\hline COL (\%área) & $2,9 \pm 0,2$ & $3,5 \pm 0,3$ & $4,0 \pm 0,4$ & $8,1 \pm 1,4^{a b}$ \\
\hline
\end{tabular}

Valores de peso corpóreo (PE), sódio plasmático $\left(\mathrm{Na}^{+}\right)$, potássio plasmático $\left(\mathrm{K}^{+}\right)$, pressão caudal (PC), albuminúria (ALB), clearance de creatinina $(\mathrm{Cl} \mathrm{Cr}$ ), porcentagem de esclerose glomerular (EG), porcentagem de lesões arteriolares (LA), porcentagem de área de expansão do interstício renal (INT) e porcentagem do córtex renal ocupado por colágeno tipo I (COL) dos grupos UNx+NS, PDTC Lact $_{+} \mathrm{UNx}+\mathrm{NS}$, UNx+SS e PDTC $\mathrm{Lact}_{+} \mathrm{UNx}+\mathrm{SS}$. Resultados apresentados como Média $\pm E P$. ( ${ }^{a} p<0.05$ vs. respectivo PDTC Lact; ${ }^{b} p<0.05$ vs. respectivo $S S$ ).

De acordo com os dados apresentados na Tabela 1 o peso corporal (PE), a concentração de sódio $\left(\mathrm{Na}^{+}\right)$e potássio $\left(\mathrm{K}^{+}\right)$plasmáticos não apresentaram alterações entre os grupos acompanhados até as 24 semanas de vida.

Na Figura 1 apresentamos os gráficos de pressão caudal, albuminúria e clerance de creatina nos 4 grupos do protocolo 1. 

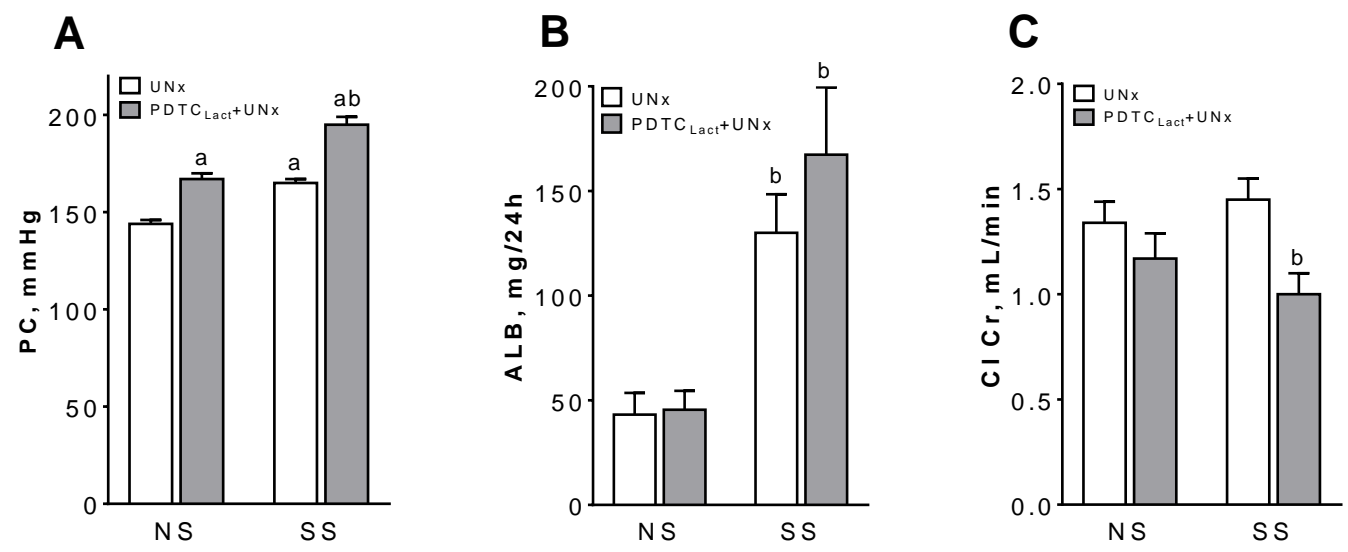

Figura 1. Valores de pressão caudal (A), albuminuria (B) e clearance de creatinina (C) dos grupos UNx+NS, PDTCLact+UNx+NS, UNx+SS e PDTCLact+UNx+SS com 24 semanas de vida. Resultados apresentados como Média \pm EP (a $p<0.05$ vs. respectivo PDTCLact; ${ }^{b} p<0.05$ vs. respectivo SS).

De acordo com a Tabela 1 a Figura 1 podemos observar que após 24 semanas, os animais do grupo PDTC Lact+UNx+NS apresentaram um aumento na pressão caudal em relação aos animais UNx+NS. O aumento na PC foi também constatado nos animais UNx+SS, indicando que a associação desses dois insultos é capaz de promover hipertensão arterial. No entanto, o aumento da PC foi mais acentuado nos animais PDTCLact+UNx+SS ( $p<0,05$ vs UNx+SS).

A excreção urinária de albumina não apresentou alterações entre os grupos acompanhados com a dieta NS, mas mostrou um aumento significativo em ambos os grupos que receberam dieta de SS. Esses resultados indicam que 0 SS altera a permeabilidade da barreira glomerular.

A função renal foi avaliada através do clearance de creatinina. Segundo os dados mostrados na Tabela 1 e Figura 1 podemos notar que não há alteração na função renal entre os animais que receberam NS, indicando que o PDTC Lact associado ao UNx não foi capaz de alterar a função renal. A SS na dieta não promoveu alteração na função renal nos animais que foram submetidos apenas a UNx. No entanto, os animais PDTCLact que foram submetidos ao duplo insulto 
(UNx e SS) apresentaram redução no clearance de creatinina, indicando perda da função nesses animais.

\section{Lesões glomerulares}

As lesões glomerulares foram quantificadas em lâminas histológicas através da técnica de PAS.
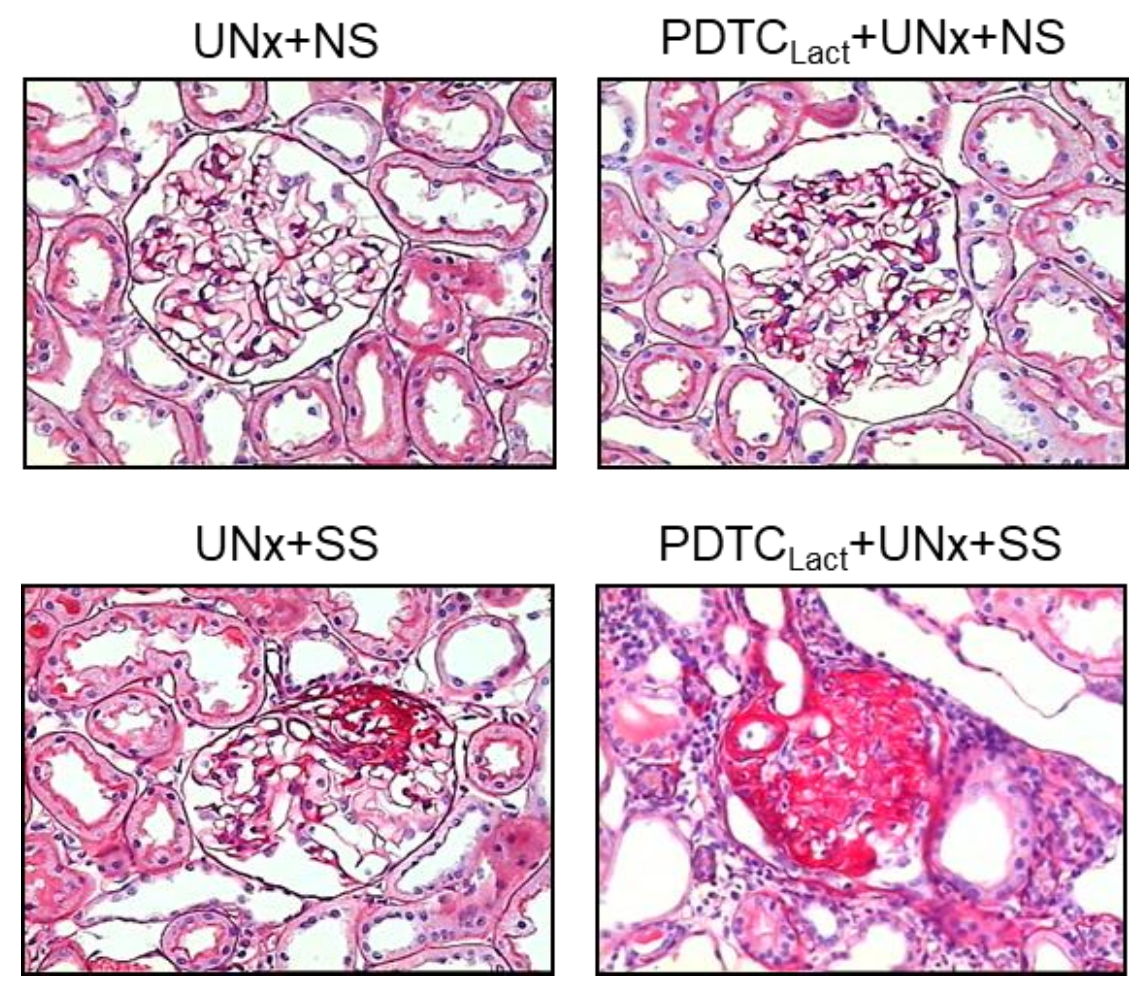

Figura 2. Microfotografias representativas de esclerose glomerular (EG) dos grupos $U N x+N S$,

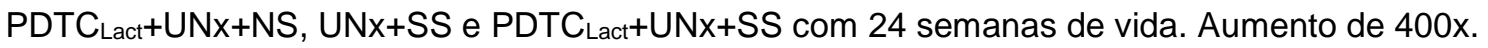



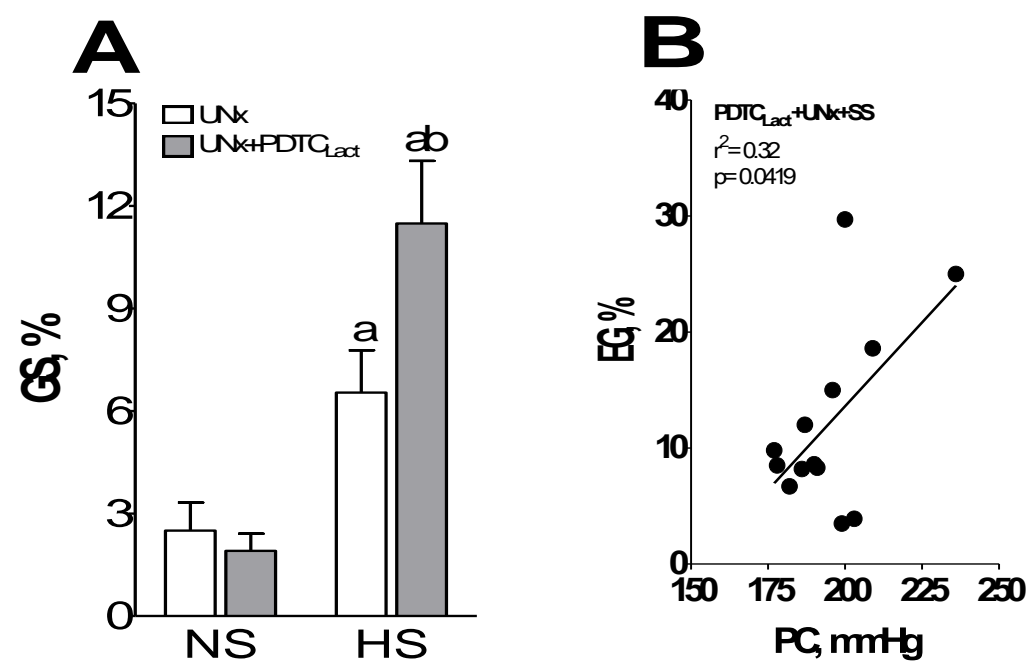

Figura 3. Valores de porcentagem de esclerose glomerular (A) dos grupos UNx+NS,

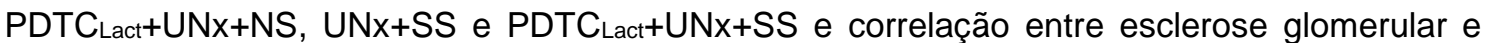
pressão caudal no grupo PDTCLact+UNx+SS (B) com 24 semanas de vida. Resultados apresentados como Média \pm EP (a $p<0.05$ vs. respectivo PDTC Lact; $^{b} p<0.05$ vs. respectivo SS).

Como podemos observar na Tabela 1 e nas Figuras 2 e 3 nos animais PDTCLact+UNx+NS não há aumento na porcentagem de EG, indicando assim que a redução da massa renal per si não provoca lesões glomerulares neste modelo. A associação UNx+SS promoveu um aumento nas lesões glomerulares em relação aos animais $U N x+N S(p<0.05)$. No entanto, a associação de $U N x+S S$ em animais PDTCLact revelou uma ampla gama de lesões renais, indicando o estabelecimento de DRC progressiva. Além disso, a PC foi agravada e correlacionou positivamente com porcentagem de esclerose glomerular $(p=0,0419)$.

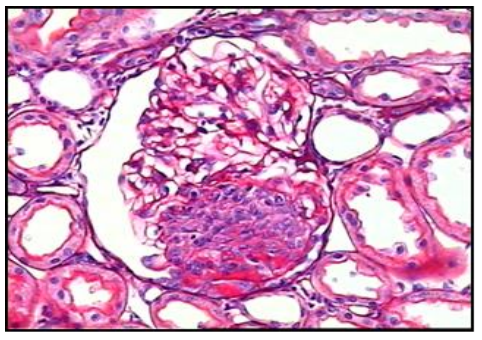

Microaneurisma

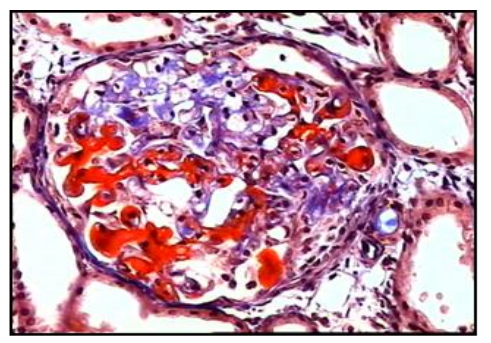

Microtrombose

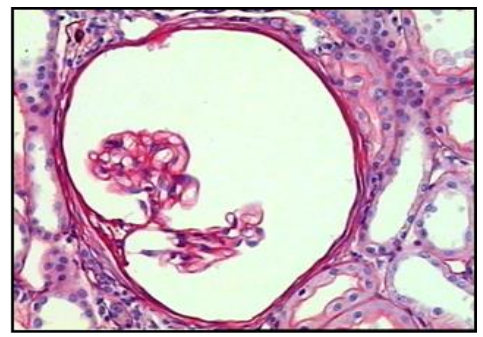

Atrofia glomerular

Figura 4. Microfotografias representativas de lesões glomerulares encontradas no grupo PDTCLact+UNx+SS. Essas lesões são classificadas como microaneurisma, microtrombose e atrofia glomerular. 
Além das lesões glomerulares do tipo esclerose, as mais frequentes na DRC, outros tipos de lesões glomerulares (Figura 4) foram observados somente nos animais do grupo PDTCLact+UNx+SS, como micro-aneurismas, microtrombose e atrofia glomerular.

\section{Lesões arteriolares}

As lesões arteriolares foram avaliadas nas lâminas coradas através de PAS.
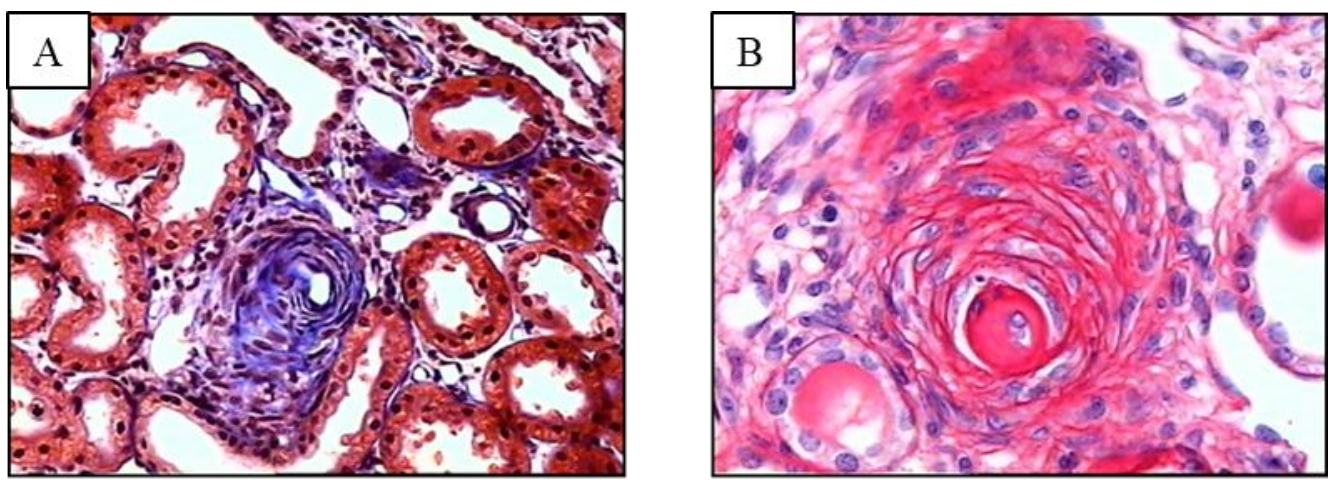

Figura 5. Microfotografias representativas de lesões arteriolares encontradas no grupo PDTC Lact $+U N x+S S$ com 24 semanas de vida. Em "A" observamos uma lesão arteriolar detectada por Tricrômio de Masson e em "B" por PAS.

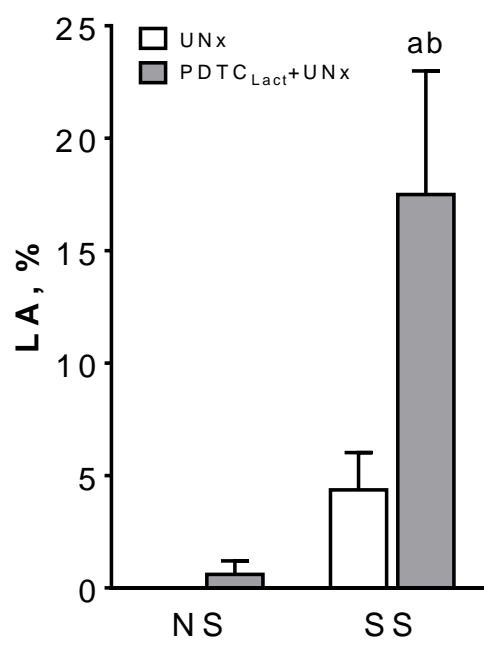

Figura 6. Valores da porcentagem de lesões arteriolares (LA) dos grupos UNx+NS,

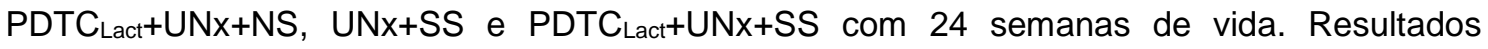
apresentados como Média \pm EP ( ${ }^{a} p<0.05$ vs. respectivo PDTC $L$ act; ${ }^{b} p<0.05$ vs. respectivo SS). 
De acordo com a Tabela 1 e as Figuras 5 e 6 os animais que receberam dieta NS não apresentaram lesões arteriolares, como no grupo UNx+NS, ou apresentaram pouquíssima LA como no grupo PDTCLact+UNx+NS $(p>0,05)$. A frequência de LA foi maior nos animais do grupo UNx+SS, mas não apresentou significância estatística quando comparado com os grupos que receberam dieta

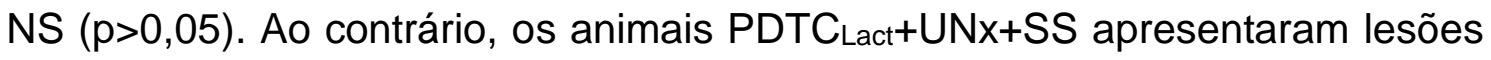
vasculares graves, com proliferação de células miointímas e necrose fibrinóidea, que estão associadas à HT severa. Estas lesões arteriolares de "casca de cebola" são frequentemente observadas em pacientes com hipertensão maligna e também foram observadas em outros modelos de hipertensão, como no modelo experimental de inibição crônica de óxido nítrico associado à SS na dieta (57).

\section{Lesões intersticiais}

A avaliação das lesões no interstício renal foi realizada através da reação com Tricrômio de Masson e da deposição de colágeno tipo I no córtex renal.
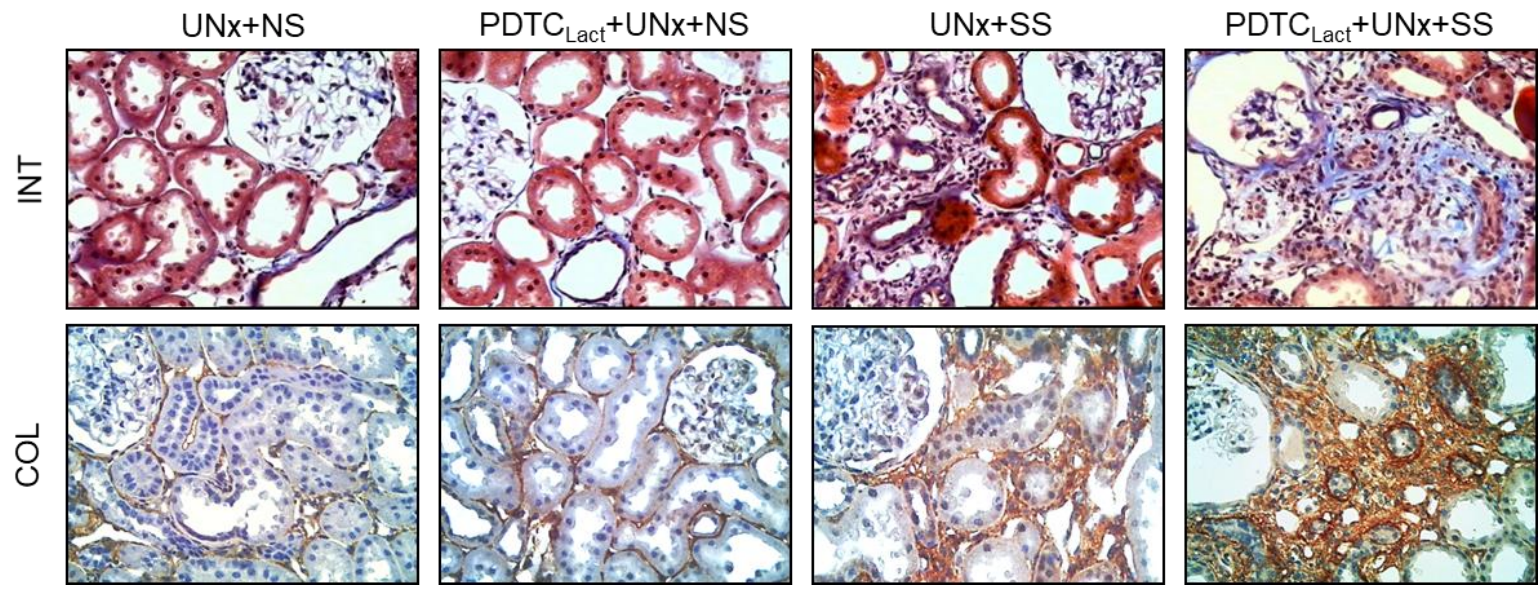

Figura 7. Microfotografias representativas da expansão do interstício renal (INT) e do córtex renal ocupado por colágeno tipo I (COL) dos grupos UNx+NS, PDTC Lact+UNx+NS, UNx+SS e PDTC Lact+UNx+SS com 24 semanas de vida. Aumento de 400x. 
A

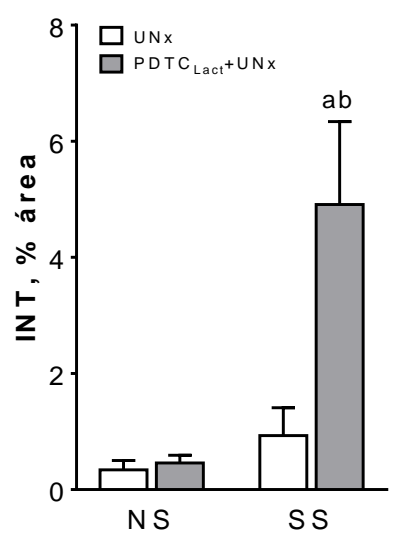

\section{B}

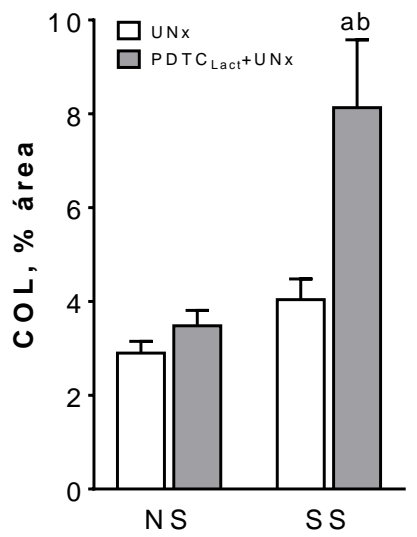

Figura 8. Os valores da porcentagem de área de expansão do interstício renal $(A)$ e valores da porcentagem do córtex renal ocupado por colágeno tipo I (B) dos grupos UNx+NS, PDTCLact+UNx+NS, UNx+SS e PDTCLact+UNx+SS com 24 semanas de vida. Resultados apresentados como Média \pm EP ( ${ }^{a} p<0.05$ vs. respectivo PDTC $L$ act; ${ }^{b} p<0.05$ vs. respectivo $S S$ ).

Como podemos observar nos dados da Tabela 1 e das Figuras 7 e 8 a área cortical com expansão intersticial foi semelhante entre os animais que receberam dieta NS $(p<0,05)$ e com discreto aumento no grupo UNx+SS. Ao contrário, a associação do UNx+SS em ratos PDTCLact promoveu um notável aumento na expansão do interstício renal, sugerindo a formação de fibrose no córtex renal. Essa lesão intersticial foi confirmada com a análise da deposição de colágeno tipo I, através da técnica de IHQ. O perfil de depósito de colágeno 1 seguiu o mesmo padrão da expansão intersticial e apresentou um exuberante aumento nos animais do grupo PDTC $L a c t+U N x+S S$, sugerindo um processo avançado que leva à substituição do parênquima renal por um tecido fibrótico $(6,9)$. 
Tabela 2. Parâmetros inflamatórios do protocolo 1

\begin{tabular}{|c|c|c|c|c|}
\hline & $\begin{array}{c}\mathrm{UNx}+\mathrm{NS} \\
\mathrm{N}=11\end{array}$ & $\begin{array}{c}\text { PDTCLact+UNx+NS } \\
\qquad N=11\end{array}$ & $\begin{array}{c}\text { UNx+SS } \\
N=13\end{array}$ & $\begin{array}{c}\text { PDTCLact+UNx+SS } \\
N=13\end{array}$ \\
\hline $\mathrm{MCP}-1(\mathrm{pg} / \mathrm{mL})$ & $671 \pm 216$ & $711 \pm 231$ & $630 \pm 176$ & $1576 \pm 276^{\mathrm{ab}}$ \\
\hline Mф Int (céls/mm²) & $33 \pm 3$ & $34 \pm 3$ & $54 \pm 6$ & $140 \pm 21^{a b}$ \\
\hline M $\phi$ Glo (céls $/ \mathrm{mm}^{2}$ ) & $10 \pm 2$ & $9 \pm 1$ & $12 \pm 2$ & $23 \pm 3^{a b}$ \\
\hline Mф Art (céls/mm²) & $0,2 \pm 0,1$ & $0,4 \pm 0,2$ & $1,5 \pm 0,5$ & $5,9 \pm 1,2^{\mathrm{ab}}$ \\
\hline Ly Int (céls/mm²) & $37 \pm 3$ & $43 \pm 4$ & $76 \pm 11$ & $130 \pm 21^{a b}$ \\
\hline Ly Glo (céls/mm²) & $0,9 \pm 0,1$ & $0,8 \pm 0,1$ & $1,0 \pm 0,3$ & $2,1 \pm 0,5^{a b}$ \\
\hline Ly Art (céls/mm²) & $0,3 \pm 0,1$ & $0,3 \pm 0,1$ & $0,6 \pm 0,2$ & $2,7 \pm 0,7^{a b}$ \\
\hline APR (céls $/ \mathrm{mm}^{2}$ ) & $3,5 \pm 0,7$ & $2,5 \pm 0,6$ & $0,1 \pm 0,1^{\mathrm{a}}$ & $0,1 \pm 0,1^{\mathrm{a}}$ \\
\hline All+ (céls $\left./ \mathrm{mm}^{2}\right)$ & $1,8 \pm 0,2$ & $2,0 \pm 0,6$ & $2,8 \pm 0,6$ & $6,8 \pm 0,8^{a b}$ \\
\hline
\end{tabular}

Valores de Monocyte Chemoattractant Protein-1 (MCP-1), macrófagos intersticiais (M $\phi$ int), macrófagos glomerulares ( $\mathrm{M} \phi$ glo), macrófagos arteriolares ( $\mathrm{M} \phi$ art), linfócitos $\mathrm{T}$ intersticiais ( $\mathrm{Ly}$ int), linfócitos T glomerulares (Ly glo), linfócitos T arteriolares (Ly art), atividade plasmática de renina (APR) e células positivas para Angiotensina II no interstício renal (All+ int) dos grupos $\mathrm{UNx}+\mathrm{NS}$, PDTC Lact $_{+} \mathrm{UNx}+\mathrm{NS}$, UNx+SS e PDTC Lact+UNx+SS. Resultados apresentados como Média \pm EP. ( ${ }^{a} p<0.05$ vs. respectivo PDTCLact; ${ }^{b} p<0.05$ vs. respectivo SS).

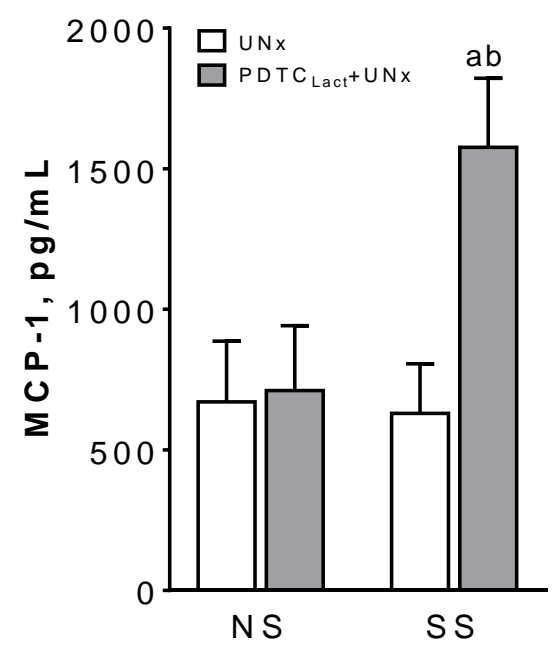

Figura 9. Valores de Monocyte Chemoattractant Protein-1 (MCP-1) dos grupos UNx+NS, PDTCLact+UNx+NS, UNx+SS e PDTCLact+UNx+SS com 24 semanas de vida. Resultados apresentados como Média \pm EP ( ${ }^{a} p<0.05$ vs. respectivo PDTC Lact; $^{\circ} p<0.05$ vs. respectivo SS). 
De acordo com a Tabela 2 e a Figura 9 os níveis séricos de MCP-1, uma citocina chave para o recrutamento de macrófagos, não apresentaram alterações significativas nos grupos acompanhados com dieta NS. Um perfil semelhante foi observado nos animais $\mathrm{UNx}+\mathrm{SS}$, indicando que apenas a sobrecarga salina não foi capaz de alterar o nível sérico de MCP-1. Por outro lado, a associação UNx+SS em ratos PDTC Lact causou um aumento drástico nos níveis séricos de MCP-1.

\section{Macrófagos}

Investigamos, através da técnica de $\mathrm{IHQ}$, a infiltração de macrófagos em diferentes compartimentos do tecido renal (intersticial, glomerular e arteriolar).
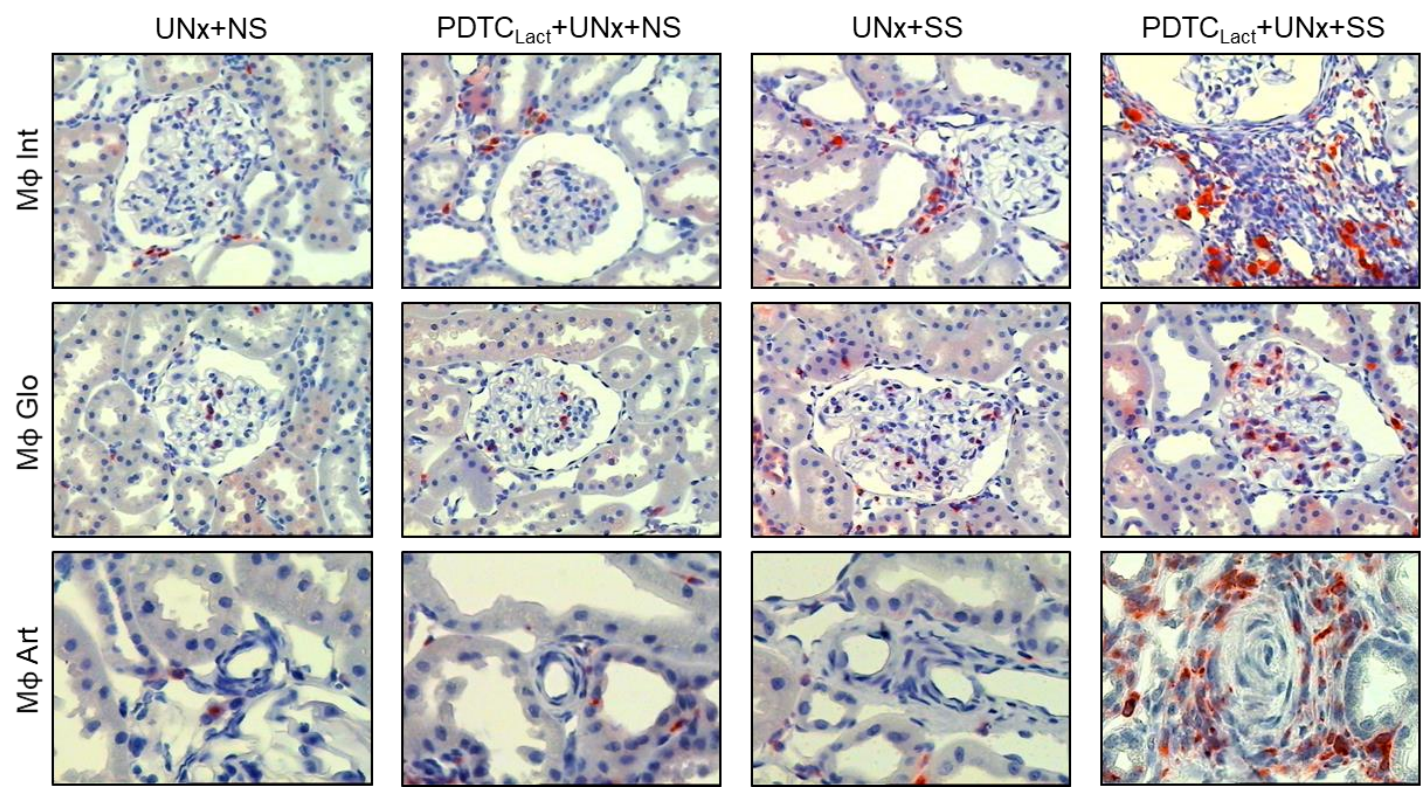

Figura 10. Microfotografias representativas de infiltração de macrófagos intersticiais, glomerulares e arteriolares dos grupos UNx+NS, PDTCLact+UNx+NS, UNx+SS e PDTCLact+UNx+SS com 24 semanas de vida. 

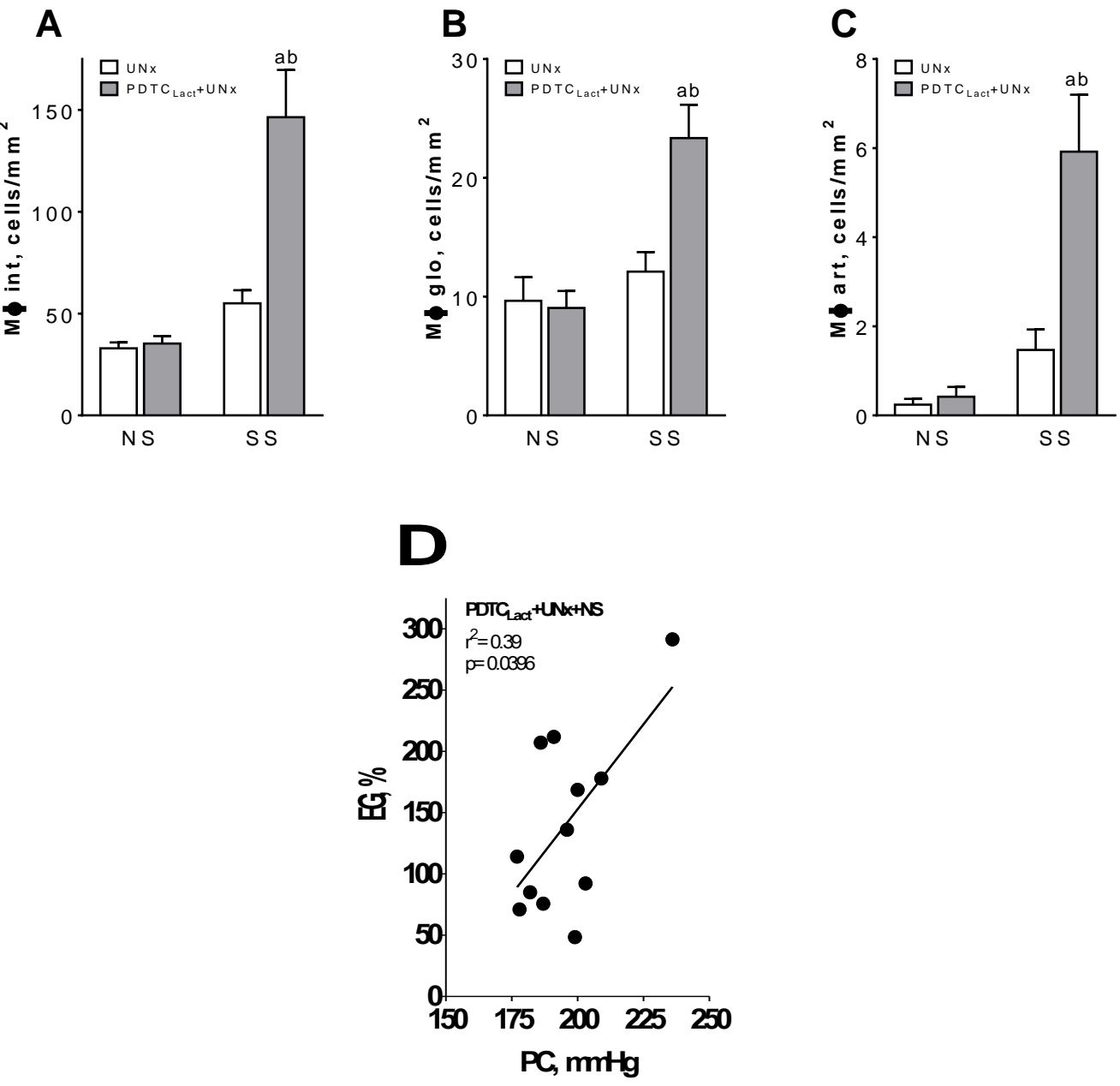

Figura 11. Valores de macrófagos intersticiais $(A)$, macrófagos glomerulares (B), macrófagos arteriolares (C) dos grupos UNx+NS, PDTC Lact+UNx+NS, UNx+SS e PDTC $\mathrm{Lact}_{+} \mathrm{UNx}+\mathrm{SS}$ e correlação entre PC e macrófagos intersticiais no grupo PDTC Lact+UNx+NS (D) com 24 semanas de vida. Resultados apresentados como Média \pm EP ( ${ }^{a} p<0.05$ vs. respectivo PDTCLact; ${ }^{b} p<0.05$ vs. respectivo SS).

Como podemos observar na Tabela 2 e nas Figuras 10 e 11 o padrão da infiltração macrofágica foi semelhante em todos os compartimentos do rim, corroborando os níveis séricos de MCP-1. Os animais do grupo PDTCLact+UNx+NS apresentaram valores semelhantes de macrófagos quando comparados com UNx+NS. No entanto, o infiltrado macrofágico intersticial dos animais que receberam PDTC durante a lactação (PDTC Lact+ $_{\text {UNx }}+\mathrm{NS}$ ) 
correlacionou positivamente com a hipertensão arterial observada nesses animais $(p=0.0396)$, indicando a presença de uma inflamação incipiente. Os animais que foram submetidos à UNx+SS apresentaram um discreto aumento numérico no infiltrado macrofágico, apesar das alterações hemodinâmicas e morfológicas. Em consonância com os níveis séricos de MCP-1, os animais do grupo PDTCLact+UNx+SS foram os únicos que apresentaram um aumento intenso no infiltrado macrofágico no compartimento intersticial, glomerular e arteriolar.

\section{Linfócitos}

Utilizando a técnica de IHQ analisamos a presença de linfócitos T no tecido renal dos animais dos grupos pertencentes ao protocolo 1.
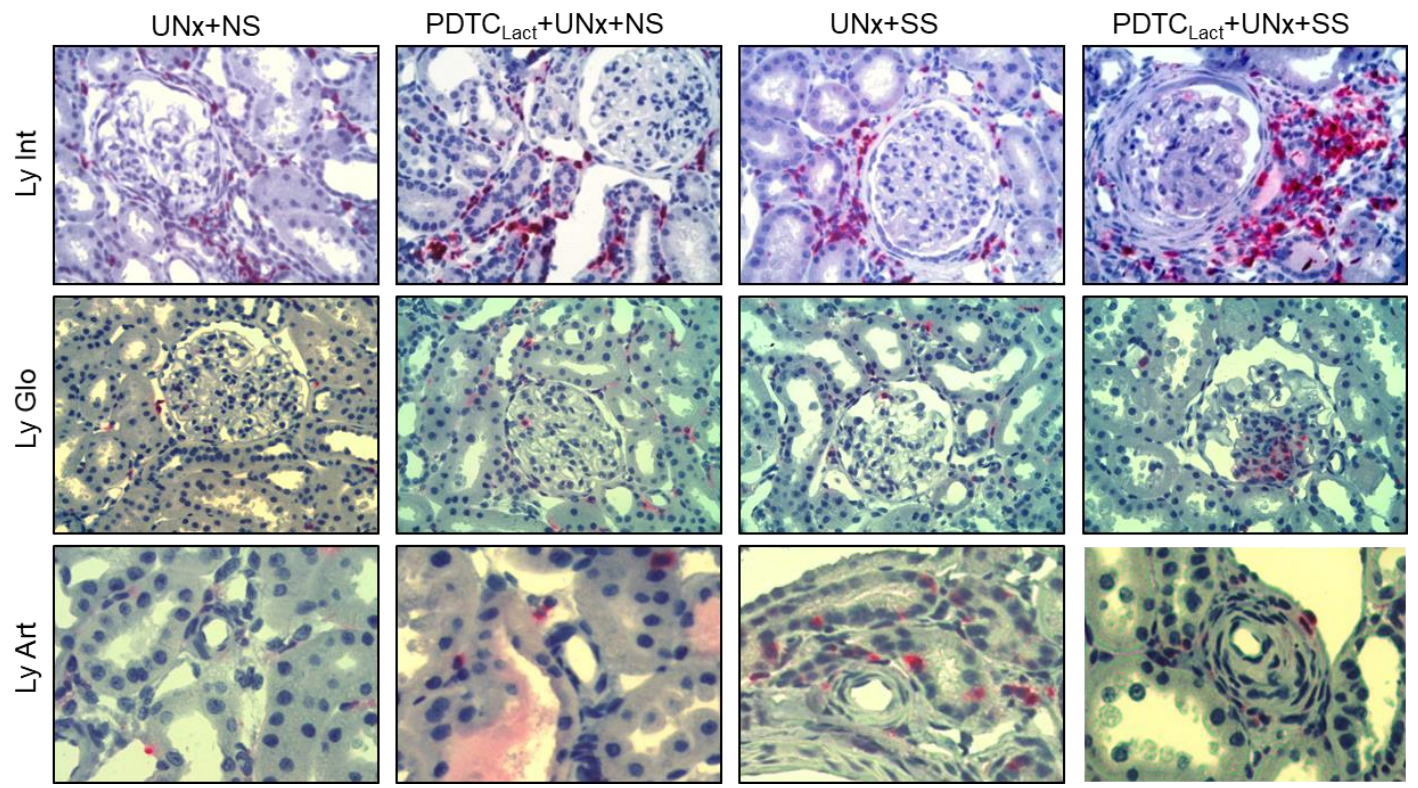

Figura 12. Microfotografias representativas de infiltração de linfócitos intersticiais, glomerulares e arteriolares dos grupos UNx+NS, PDTC Lact $+U N x+N S$, UNx+SS e PDTCLact+UNx+SS com 24 semanas de vida. 
A

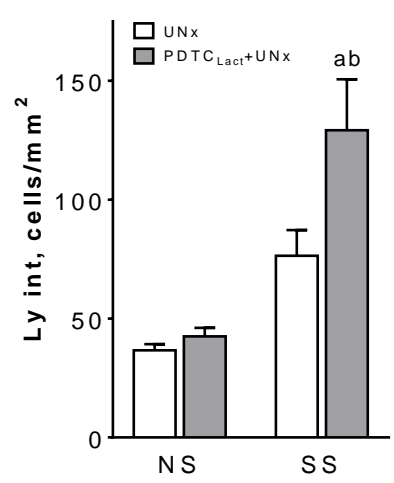

B

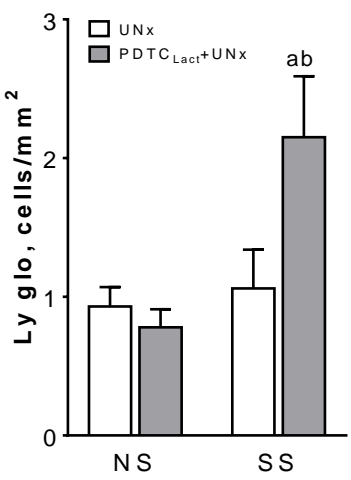

C

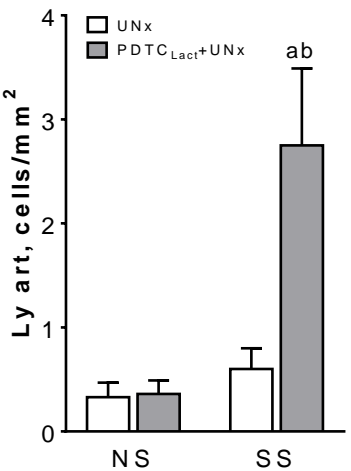

Figura 13. Valores de linfócitos $T$ intersticiais (A), linfócitos $T$ glomerulares (B) e linfócitos $T$ arteriolares (C) dos grupos $U N x+N S$, PDTC Lact $\mathrm{UNx}+\mathrm{NS}$, UNx+SS e $\mathrm{PDTC}_{\text {Lact }}+\mathrm{UNx}+\mathrm{SS}$ com 24 semanas de vida. Resultados apresentados como Média \pm EP $\left({ }^{a} p<0.05\right.$ vs. respectivo PDTC ${ }_{\text {Lact; }}{ }^{b} p<0.05$ vs. respectivo SS).

Como podemos observar na Tabela 2 e nas Figuras 12 e 13 o padrão do infiltrado linfocitário nos grupos avaliados foi semelhante ao observado no infiltrado macrofágico.

\section{Sistema renina-agiotensina}

Sabe-se que o sistema renina-angiotensina-aldosterona (SRAA) participa da progressão da DRC. Com o intuito de verificar se havia alteração na atividade do SRAA nos grupos que receberam NS e SS, a atividade sistêmica (APR) e a local (All tecidual) foram avaliadas após 24 semanas de vida.
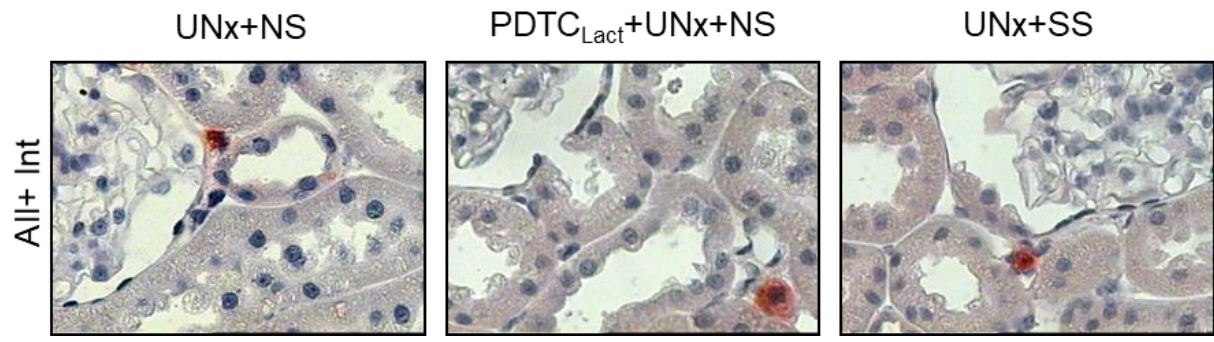

PDTC $_{\text {Lact }}+U N x+S S$

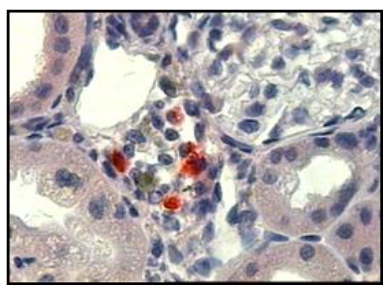

Figura 14. Microfotografias representativas de células positivas para angiotensina II no interstício renal dos grupos UNx+NS, PDTCLact+UNx+NS, UNx+SS e PDTCLact+UNx+SS com 24 semanas de vida. 
A

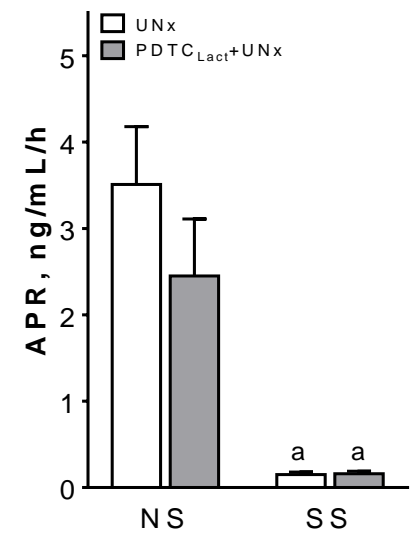

B

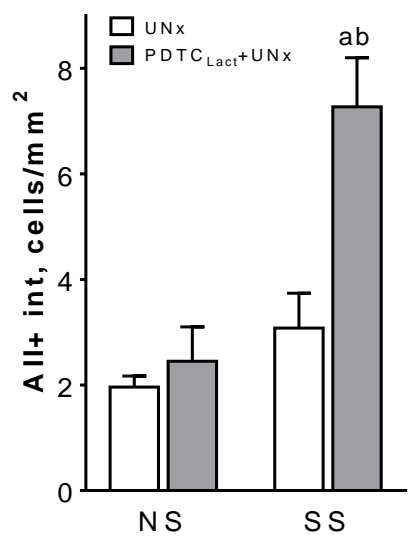

Figura 15. Valores de atividade plasmática de renina $(A)$ e células positivas para Angiotensina II no interstício renal (B) dos grupos UNx+NS, PDTCLact+UNx+NS, UNx+SS e PDTC Lact+UNx+SS com 24 semanas de vida. Resultados apresentados como Média $\pm E P$ $\left({ }^{a} p<0.05\right.$ vs. respectivo PDTC Lact; $^{\text {b }} p<0.05$ vs. respectivo SS).

De acordo com os dados da Tabela 1 e das Figuras 14 e 15 a APR e a quantidade de células positivas para All foram semelhantes nos dois grupos de animais que receberam a dieta NS, indicando que o tratamento com PDTC durante a lactação não alterou o SRAA circulante e o local. No entanto, os animais de ambos os grupos que receberam dieta SS apresentam uma notável queda da atividade da renina, indicando a inibição do SRAA na circulação desses animais. Embora a dieta SS tenha reduzido drasticamente a atividade do SRAA sistêmica, as células positivas para All no interstício renal estava aumentada no grupo PDTC $\mathrm{Lact}_{+} \mathrm{UNx}+\mathrm{SS}$, possivelmente produzidas por células inflamatórias. Esses dados mostram que há uma dissociação entre a atividade do SRAA sistêmico e a produzida localmente no tecido renal. 
Tabela 3. Vias de sinalização intracelular e estresse oxidativo no protocolo 1

\begin{tabular}{|c|c|c|c|c|}
\hline & $\begin{array}{c}\mathrm{UNx}+\mathrm{NS} \\
\mathrm{N}=8\end{array}$ & $\begin{array}{c}\text { PDTC } \text { Lact }_{\text {L }} \text { UNx+NS } \\
\mathrm{N}=8\end{array}$ & $\begin{array}{c}U N x+S S \\
N=8\end{array}$ & $\begin{array}{c}\text { PDTC }_{\text {Lact }}+U N x+S S \\
N=8\end{array}$ \\
\hline TLR4 (x UNx+NS) & $1,0 \pm 0,1$ & $1,5 \pm 0,5$ & $1,1 \pm 0,2$ & $2,9 \pm 0,7^{a b}$ \\
\hline p65 fosf (x UNx+NS) & $1,0 \pm 0,2$ & $1,1 \pm 0,2$ & $0,9 \pm 0,1$ & $2,0 \pm 0,2^{\mathrm{ab}}$ \\
\hline IL-6 (x UNx+NS) & $1,0 \pm 0,1$ & $0,9 \pm 0,2$ & $1,2 \pm 0,1$ & $1,8 \pm 0,4^{a}$ \\
\hline $\mathrm{HO}-1(x \cup N x+N S))$ & $1,0 \pm 0,1$ & $1,4 \pm 0,7$ & $1,6 \pm 0,5$ & $1,9 \pm 0,2^{a}$ \\
\hline MnSOD (x UNx+NS) & $1,0 \pm 0,1$ & $0,9 \pm 0,2$ & $0,8 \pm 0,2$ & $0,5 \pm 0,1^{a b}$ \\
\hline
\end{tabular}

Valores de Toll-like receptor (TLR4), conteúdo nuclear de p65 fosforilado no tecido renal (p65 fosf), conteúdo proteico renal de interleucina-6 (IL-6), Heme oxygenase 1 (HO-1) e conteúdo proteico renal de Mitochondrial antioxidant manganese superoxide dismutase (MnSODS) dos grupos $\mathrm{UNx}+\mathrm{NS}$, PDTCLact+UNx+NS, UNx+SS e PDTCLact+UNx+SS. Resultados apresentados como Média $\pm E P$. ( ${ }^{a} p<0.05$ vs. respectivo PDTC Lact; ${ }^{b} p<0.05$ vs. respectivo $S S$ ).

\section{Via de ativacão do sistema NF-KB}

A
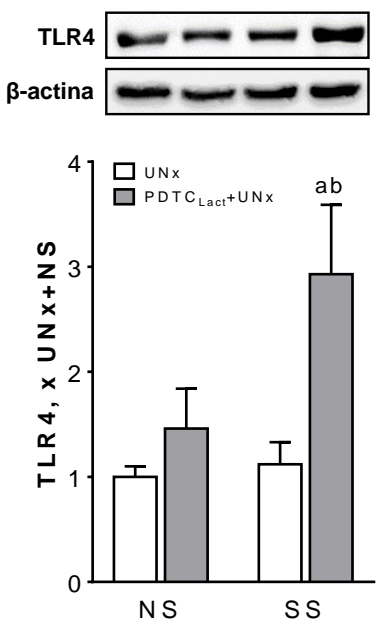

B
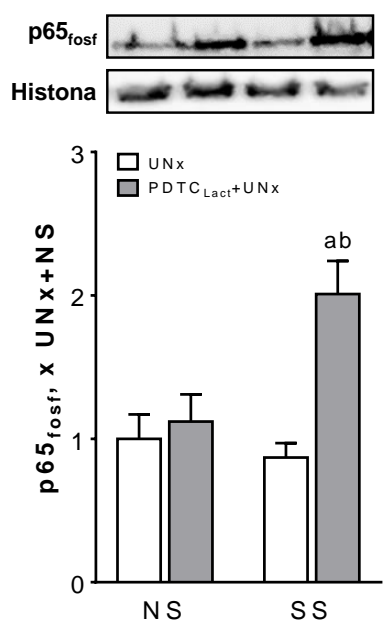
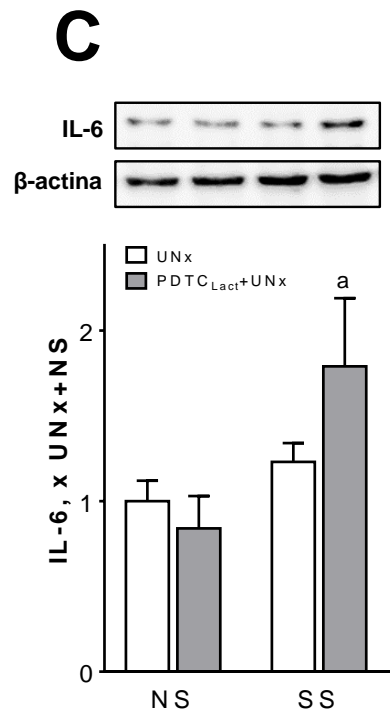

Figura 16. Valores do conteúdo proteico renal de Toll-like receptor (A), conteúdo nuclear de p65 fosforilado no tecido renal (B) e conteúdo proteico renal de interleucina-6 (C) dos grupos $\mathrm{UNx}+\mathrm{NS}$, PDTC $\mathrm{Lact}_{+} \mathrm{UNx}+\mathrm{NS}$, UNx+HS e PDTC $\mathrm{Lact}_{+} \mathrm{UNx}+\mathrm{HS}$ com 24 semanas de vida. Resultados apresentados como Média \pm EP (a $p<0.05$ vs. respectivo $P D T C_{\text {Lact }}$; ${ }^{b} p<0.05$ vs. respectivo SS). 
Sabe-se que a ativação do receptor TLR4 pode dar início a um complexo sistema de sinalização intracelular e aumentar a expressão de agentes próinflamatórios. Segundo os dados da Tabela 3 e Figura 16 analisamos o conteúdo proteico do receptor TLR4 no tecido renal e observamos que nos animais PDTCLact+UNx+NS não houve diferença nos níveis de TLR4 em relação aos animais $U N x+N S(p>0,05)$. A SS na dieta não promoveu aumento do TLR4 no tecido renal dos animais UNx+SS. Já no grupo PDTCLact+UNx+SS, o conteúdo proteico do TLR4 de estava aumentado, indicando a participação de elementos da imunidade inata no processo inflamatório deste modelo. A ativação do sistema NF-KB ocorre através da translocação da subunidade p65 para o núcleo. No presente estudo, através da medida de p65 no núcleo das células do tecido renal, nós mostramos um aumento expressivo na atividade do sistema NF-kB, indicando que, paradoxalmente, os animais que tiveram esse sistema inibido durante a lactação apresentaram uma ativação exacerbada do sistema NF-kB em resposta à dieta UNx e SS na idade adulta. Alguns dos agentes próinflamatórios que são decorrentes da ativação do sistema NF-kB são as citocinas, como a interleucina 6 (IL-6). Essa citocina está presente em muitos modelos experimentais de hipertensão e dano renal e pode ser um dos agentes responsáveis pela perpetuação da inflamação. Corrobrando essa hipóstese, o conteúdo renal de IL-6 estava aumentado apenas nos animais do grupo PDTCLact+UNx+SS, que apresentaram ativação do sistema NF-KB. 


\section{Estresse oxidativo}

Um mecanismo que desempenha um papel importante no processo inflamatório de várias doenças como HT e DRC é a atividade de agentes oxidantes capazes de modular as vias de sinalização celular dependentes de redox. A heme-oxygenase 1 e a MnSOD são enzimas responsáveis pela proteção contra o estresse oxidativo em várias doenças inflamatórias, incluindo hipertensão e doenças renais (60-62).
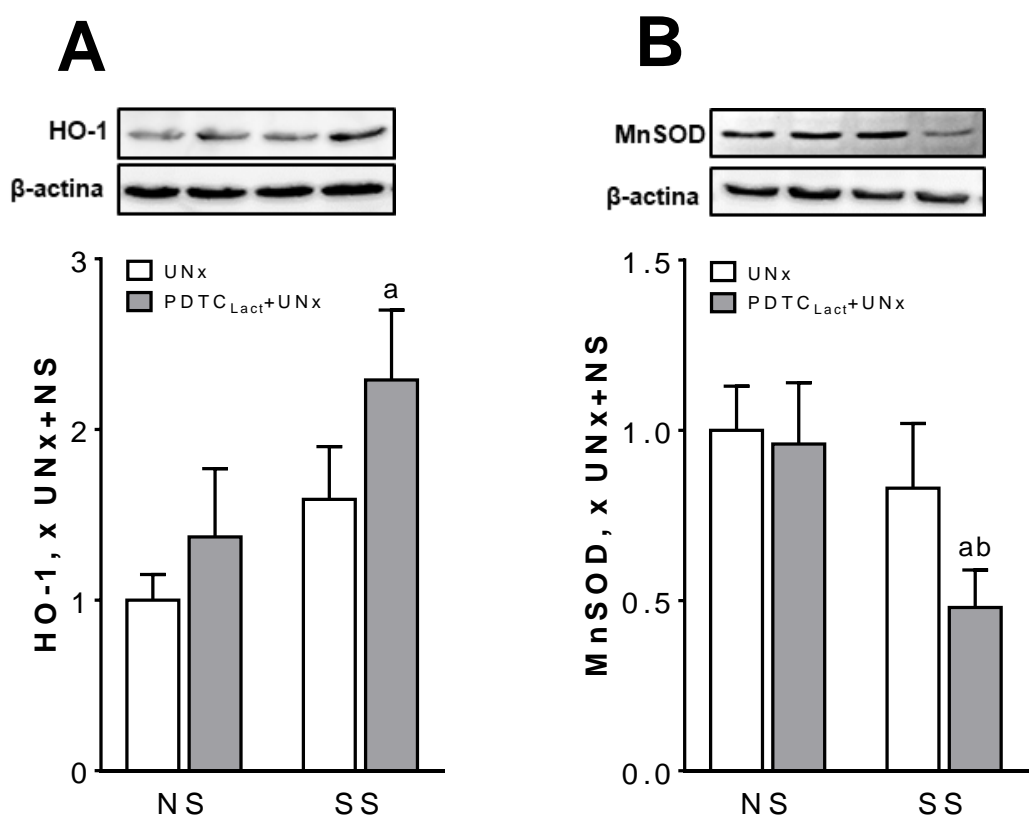

Figura 17. Valores do conteúdo proteico renal de Heme oxygenase 1 (A) e conteúdo proteico renal de Mitochondrial antioxidant manganese superoxide dismutase (B) dos grupos UNx+NS, PDTC $_{\text {Lact }}+\mathrm{UNx}+\mathrm{NS}$, UNx+SS e PDTC $\mathrm{Lact}_{+} \mathrm{UNx}+\mathrm{SS}$ com 24 semanas de vida. Resultados apresentados como Média \pm EP (ap $<0.05$ vs. respectivo $P D T C_{L a c t}$; $p<0.05$ vs. respectivo SS).

Segundo os dados apresentados na Tabela 3 e na Figura 17 os animais que receberam NS não apresentaram alterações nos parâmetros que indicam estresse oxidativo. Apesar de algumas alterações hemodinâmicas e morfológicas, os animais do grupo UNx+SS também não apresentaram alterações nas duas enzimas analisadas. Por outro lado, os animais do grupo PDTCLact+UNx+SS mostraram um aumento na Heme Oxigenase 1 renal (HO- 
1), sugerindo a necessidade de proteção contra a citotoxicidade causada por espécies reativas de oxigênio. Além disso, esses animais mostraram uma redução do MnSOD renal, sugerindo que os ratos do grupo PDTCLact+UNx+SS apresentam uma disfunção mitocondrial e deficiência no sistema de remoção de espécies reativas de oxigênio. 


\subsection{Protocolo 2}

Para investigar a participação do SRAA na progressão das lesões renais nos animais PDTCLact+UNx+SS, nós administramos Losartan nesses animais. A seguir serão apresentados os resultados obtidos ao final das 24 semanas de vida dos animais PDTC Lact $_{+} U N x+S S$ e PDTC Lact $_{+} U N x+S S+L$ pertencentes ao protocolo 2.

Tabela 4. Parâmetros gerais do protocolo 2

PDTC Lact+UNx+SS

$\mathrm{N}=10$

$355 \pm 6$

$143 \pm 1,0$

$4,4 \pm 0,2$

$197 \pm 6$

$152 \pm 39$

$0,8 \pm 0,1$

$E G(\%)$

$12 \pm 2$

$20 \pm 7$

$4,6 \pm 1,5$

INT (\%)

$9,2 \pm 1,6$

$\mathrm{COL}(\%)$

$$
9,2 \pm 1,6
$$

PDTCLact+UNx+SS+L

$\mathrm{N}=10$

$367 \pm 9$

$142 \pm 1,0$

$3,9 \pm 0,2$

$166 \pm 4$ *

$77 \pm 17$

$1,3 \pm 0,1^{*}$

$7 \pm 1^{*}$

$10 \pm 4$

$1,5 \pm 0,8^{*}$

$4,7 \pm 0,8^{*}$

Valores de peso corpóreo $(\mathrm{PE})$, sódio plasmático $\left(\mathrm{Na}^{+}\right)$, potássio plasmático $\left(\mathrm{K}^{+}\right)$, pressão caudal (PC), albuminuria (ALB), clearance de creatinina $(\mathrm{Cl} \mathrm{Cr})$, porcentagem de esclerose glomerular (EG), porcentagem de lesões arteriolares (LA), porcentagem de expansão intersticial (INT) e porcentagem de área do córtex renal ocupada por colágeno tipo 1 (COL) dos grupos PDTC $L_{\text {Lact }}+\mathrm{UNx}+\mathrm{SS}$ e PDTC $\mathrm{Lact}_{+} \mathrm{UNx}+\mathrm{SS}+\mathrm{L}$. Resultados apresentados como Média \pm EP. $\left({ }^{*} \mathrm{p}<0.05\right.$ vs. PDTC $\left.\mathrm{Lact}_{+} \mathrm{UNX}+\mathrm{SS}\right)$.

Segundo os dados da Tabela 4 podemos observar que o tratamento com Losartan não promoveu alterações na $\mathrm{PE}, \mathrm{Na}^{+}$e $\mathrm{K}^{+}$após 24 semanas de vida. 
Nos gráficos a seguir, a linha tracejada indica os animais do grupo UNx+NS do protocolo 1, que servirá apenas como uma referência e não será utilizado na análise estatística do protocolo 2.
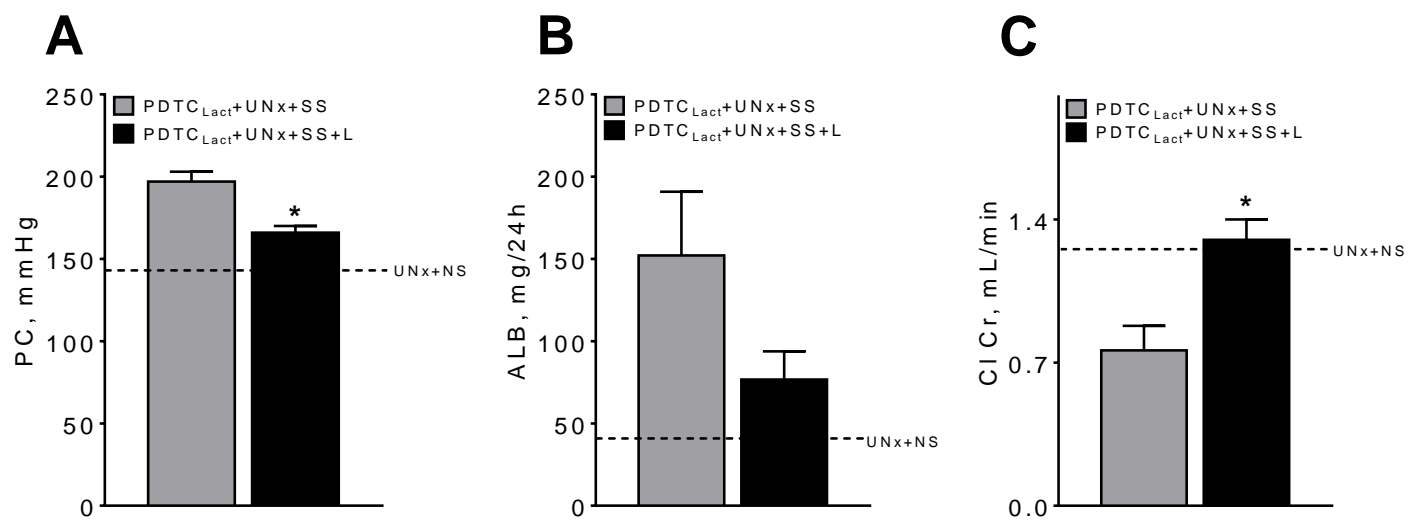

Figura 18. Valores de pressão caudal $(A)$, albuminúria $(B)$ e clearance de creatinina $(C)$ dos grupos PDTC $\mathrm{Lact}_{+}+\mathrm{UNx}+\mathrm{SS}$ e PDTC $\mathrm{Lact}_{+}+\mathrm{UNx}+\mathrm{SS}+\mathrm{L}$. Resultados apresentados como Média $\pm E P\left({ }^{*} p<0.05\right.$ vs. PDTC Lact $\left.+U N x+S S\right)$.

Como podemos observar na Tabela 4 na Figura 18 o tratamento com Losartan atenuou a pressão caudal nos animais do grupo PDTC $\mathrm{Lact}_{+} \mathrm{UNx}+\mathrm{SS}+\mathrm{L}$ $(p<0,05)$. Embora a albuminúria não tenha apresentado uma queda significativa $(p>0,05)$ entre os grupos analisados, podemos observar que nos animais que receberam Losartan houve uma prevenção da perda da função renal, como podemos observar nos níveis de $\mathrm{Cl} \mathrm{Cr}$ próximos aos dos animais do grupo $\mathrm{UNx}+\mathrm{NS}$ pertencentes ao protocolo 1 . 


\section{Lesões renais}
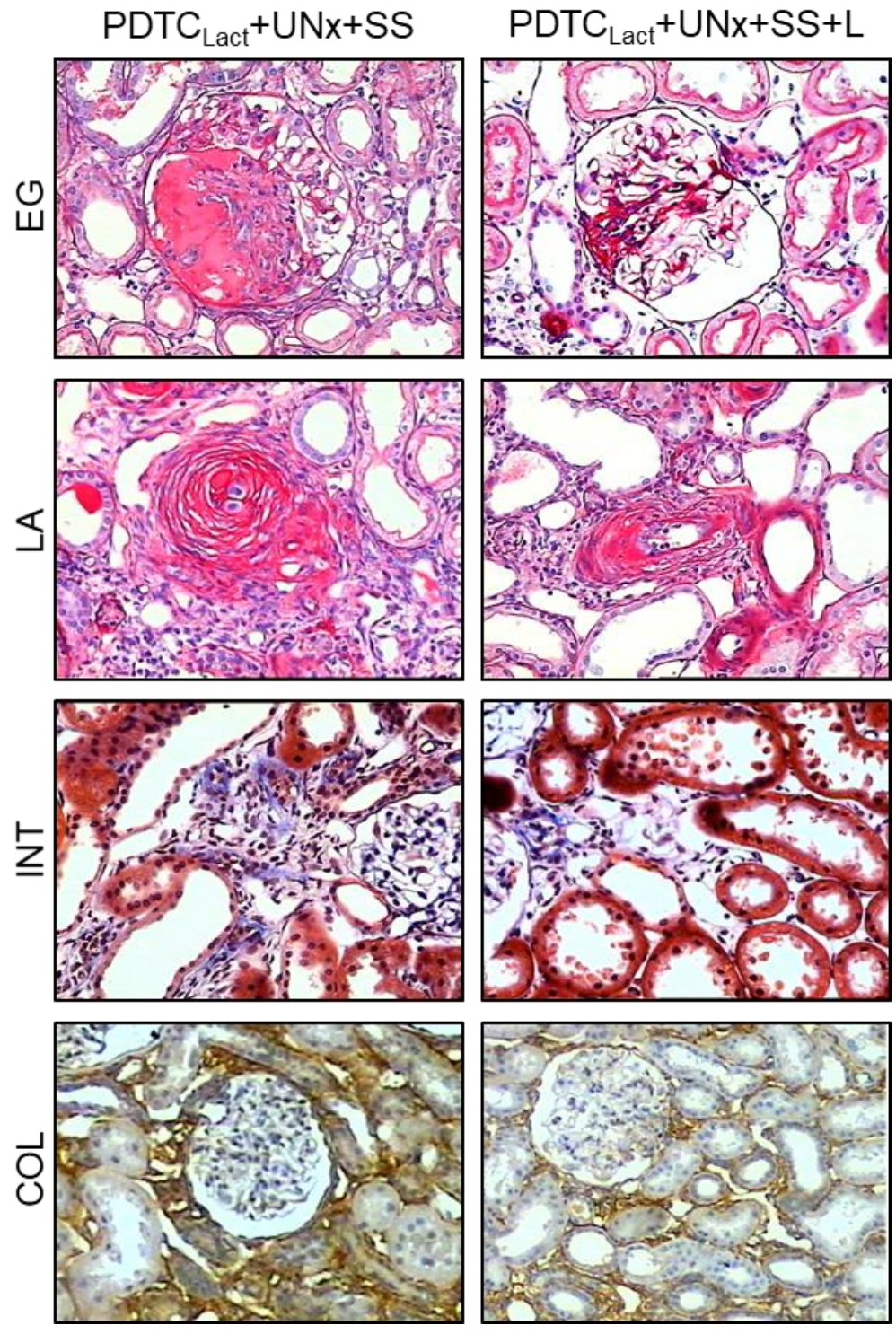

Figura 19. Microfotografias representativas de esclerose glomerular (EG), lesões arteriolares (LA), expansão do intesício renal (INT) e área do córtex renal ocupada por colágeno tipo I (COL)

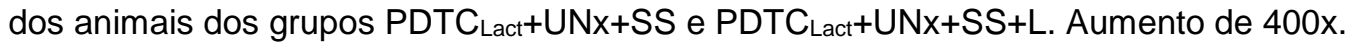


A

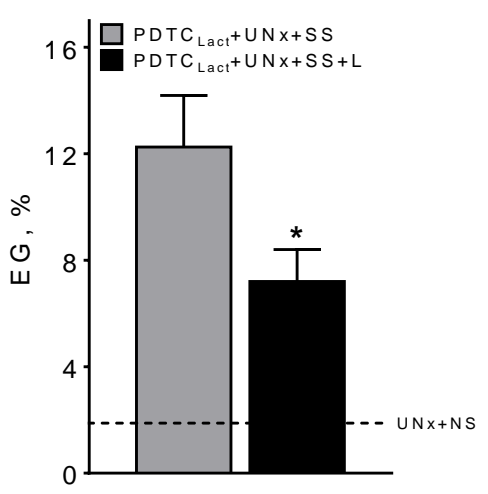

B

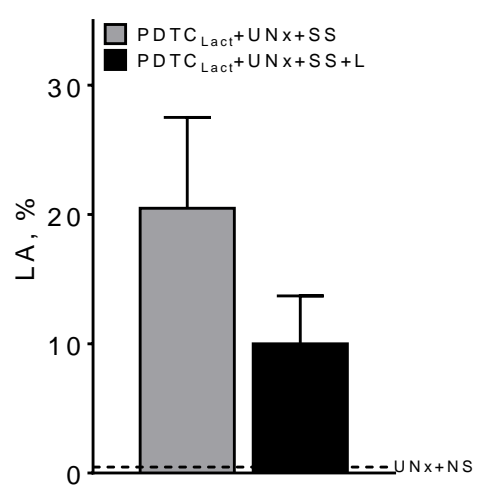

Figura 20. Valores de porcentagem de esclerose glomerular $(A)$ e porcentagem de lesões arteriolares (B) dos grupos PDTC Lact $_{+} \mathrm{UNx}+\mathrm{SS}$ e PDTC $\mathrm{Lact}_{\text {L }}+\mathrm{UNx}+\mathrm{SS}+\mathrm{L}$ com 24 semanas de vida. Resultados apresentados como Média $\pm E P \quad\left({ }^{*} \mathrm{p}<0.05\right.$ vs. PDTC $_{\text {Lact }}+U N x+S S$ ).

De acordo com a Tabela 4 e as Figuras 19 e 20 o tratamento com Losartan atenuou a porcentagem de esclerose glomerular nos animais do grupo PDTCLact+UNx+SS+L $(p<0,05)$. No entanto, as lesões arteriolares foram reduzidas apenas numericamente com o Losartan, não sendo possível verificar uma diferença estatisticamente significativa ( $p>0.05)$.

A

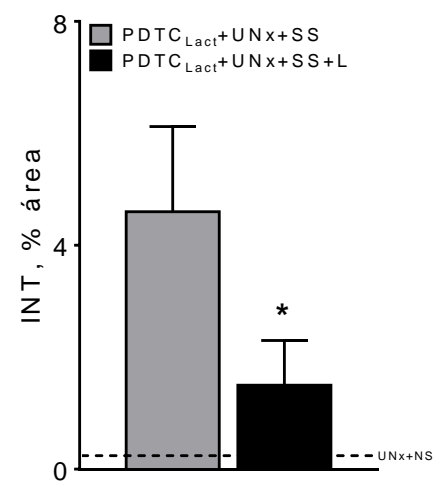

B

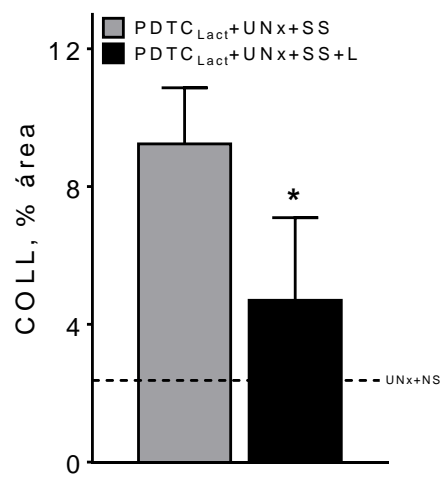

Figura 21. Valores porcentagem de expansão intersticial $(A)$ e porcentagem de área do córtex

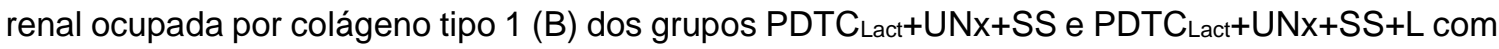
24 semanas de vida. Resultados apresentados como Média $\pm E P\left({ }^{*} p<0.05\right.$ vs. PDTC Lact $_{+} U N x+S S$ ). 
De acordo com a Tabela 4 e as Figuras 19 e 21, a expansão intersticial e a deposição de colágeno tipo I no córtex renal apresentaram uma diminuição significativa nos animais do grupo tratado com Losartan. Esses resultados indicam que o SRAA participa da progressão das lesões glomerulares e intersticias em ratos PDTC Lact Submetidos a UNx+SS.

Tabela 5. Parâmetros inflamatórios do protocolo 2

\begin{tabular}{|c|c|c|}
\hline & $\begin{array}{c}\text { PDTCLact+UNx+SS } \\
\qquad N=10\end{array}$ & $\begin{array}{c}\text { PDTC }_{\text {Lact }+} \text { UNx }+S S+L \\
N=10\end{array}$ \\
\hline MCP-1 $(\mathrm{pg} / \mathrm{mL})$ & $1803 \pm 323$ & $929 \pm 240^{*}$ \\
\hline Mф int (céls/mm²) & $154 \pm 30$ & $43 \pm 7^{*}$ \\
\hline Mф glo (céls/mm²) & $21 \pm 3$ & $8 \pm 2^{*}$ \\
\hline Mф art (céls/mm²) & $4,4 \pm 1,2$ & $1,9 \pm 0,7$ \\
\hline Ly int (céls $/ \mathrm{mm}^{2}$ ) & $141 \pm 31$ & $65 \pm 8^{*}$ \\
\hline Ly glo (céls/mm²) & $2,2 \pm 0,7$ & $0,7 \pm 0,2^{*}$ \\
\hline Ly art (céls $\left./ \mathrm{mm}^{2}\right)$ & $2,8 \pm 1,0$ & $0,9 \pm 0,2$ \\
\hline APR (ng/mL/h) & $0,11 \pm 0,1$ & $0,4 \pm 0,1^{*}$ \\
\hline All+ int (céls $\left./ \mathrm{mm}^{2}\right)$ & $8,0 \pm 1,3$ & $4,7 \pm 0,5^{\star}$ \\
\hline
\end{tabular}

Valores de Monocyte Chemoattractant Protein-1 (MCP-1), macrófagos intersticiais (M $\phi$ int), macrófagos glomerulares (M $\phi$ glo), macrófagos arteriolares ( $M \phi$ art), linfócitos $T$ intersticiais ( $L y$ int), linfócitos $T$ glomerulares (Ly glo), linfócitos $T$ arteriolares (Ly art, atividade plasmática de renina (APR) e células positivas para Angiotensina II no interstício renal (All+ int) dos grupos

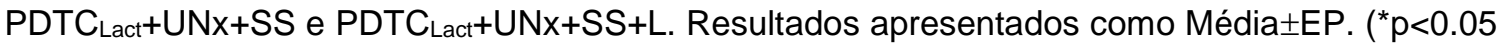
vs. PDTC $\mathrm{Lact}_{+} \mathrm{UNx}+\mathrm{SS}$ ). 


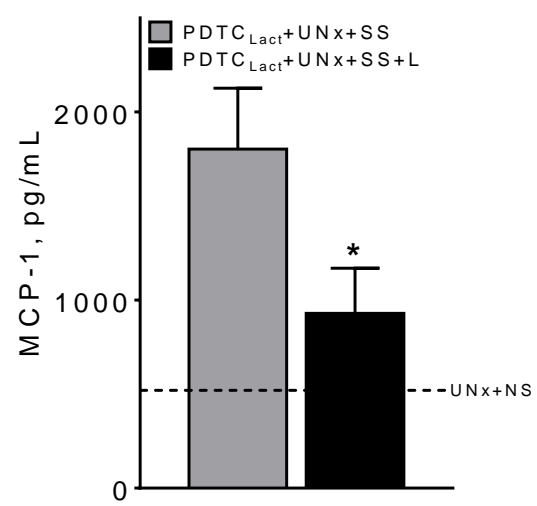

Figura 22. Valores de Monocyte Chemoattractant Protein-1 dos grupos PDTC Lact $_{+} \mathrm{UNx}+\mathrm{SS}$ e PDTC Lact+UNx+SS+L com 24 semanas de vida. Resultados apresentados como Média $\pm E P$ $\left({ }^{*} p<0.05\right.$ vs. PDTCLact $\left.+U N x+S S\right)$.

De acordo com a Tabela 5 e a Figura 22 podemos observar que 0 aumento exagerado dos níveis séricos de MCP-1 observado no grupo PDTC Lact+UNx+SS foi prevenido após tratamento com Losartan.

\section{Macrófagos}

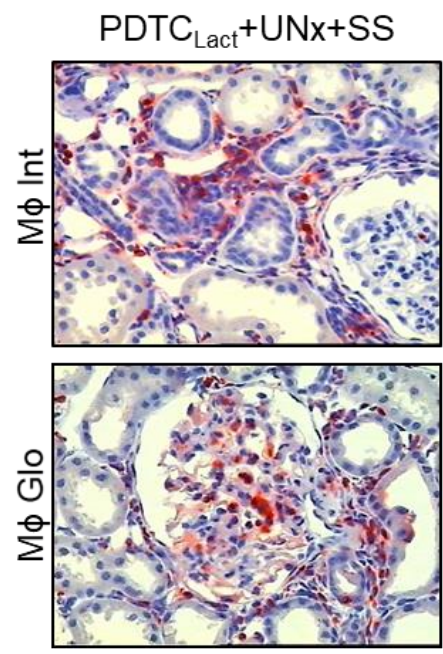

PDTC $_{\text {Lact }}+U N x+S S+L$
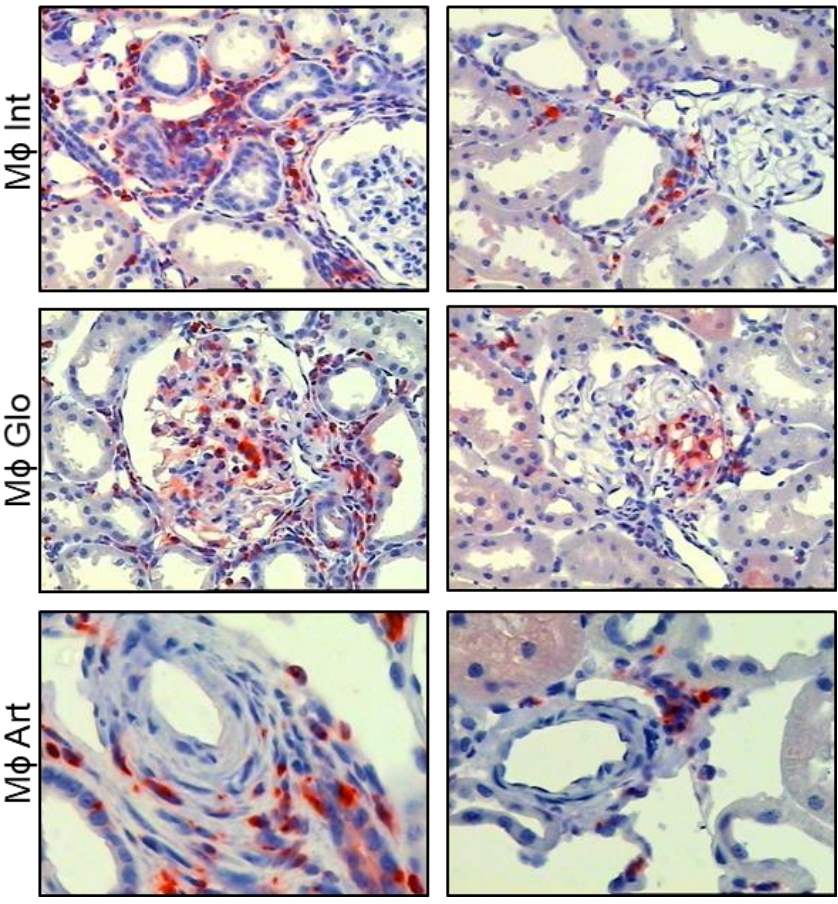

Figura 23. Microfotografias representativas de macrófagos no tecido renal dos grupos PDTC Lact+UNx+SS e PDTCLact+UNx+SS+L com 24 semanas de vida. 
A

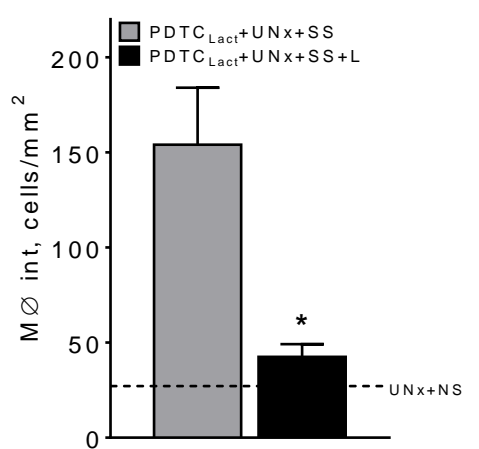

B

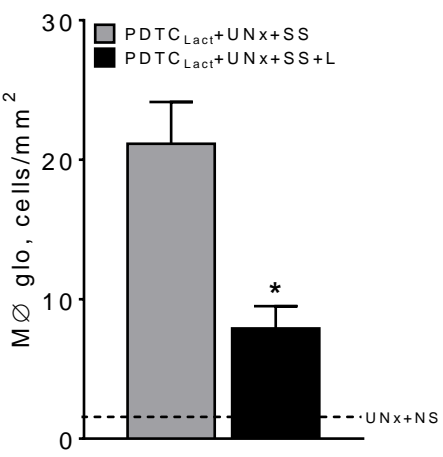

C

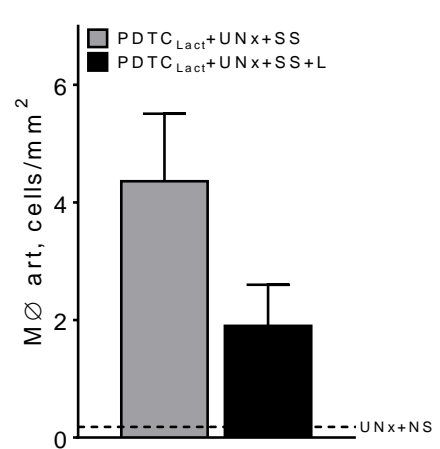

Figura 24. Valores de macrófagos intersticiais (A), macrófagos glomerulares $(B)$ e macrófagos

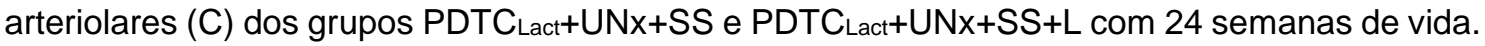
Resultados apresentados como Média \pm EP ( ${ }^{*} p<0.05$ vs. PDTC Lact $\left._{+} \mathrm{UNx}+\mathrm{SS}\right)$.

Os dados apresentados na Tabela 5 e nas Figuras 23 e 24 mostram que 0 tratamento com Losartan atenuou o quadro inflamatório observado nos animais do grupo PDTCLact+UNx+SS, constatado nos níveis séricos de MCP-1 e na infiltração de macrófagos no interstício renal e nos glomérulos. Assim como foi observado nas lesões arteriolares, o tratamento com Losartan reduziu apenas numericamente a infiltração de macrófagos nos vasos, não presentando uma diminuição estatisticamente significativa. 


\section{Linfócitos}

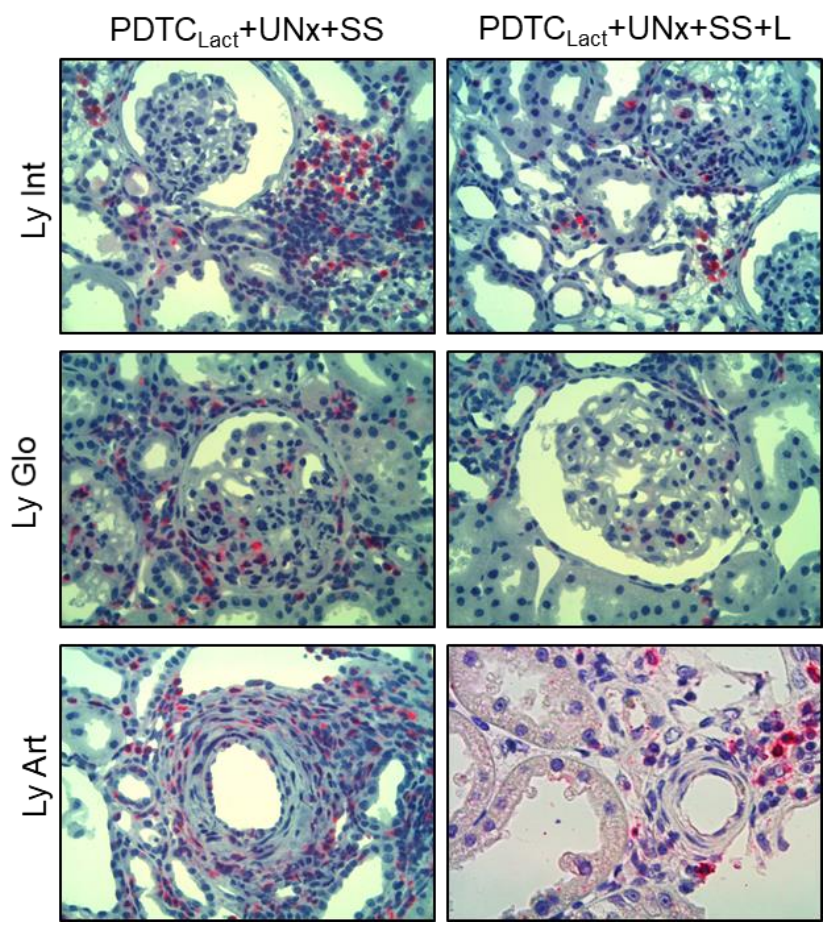

Figura 25. Microfotografias representativas de linfócitos no tecido renal dos grupos PDTCLact+UNx+SS e PDTC Lact+UNx+SS+L com 24 semanas de vida.

A

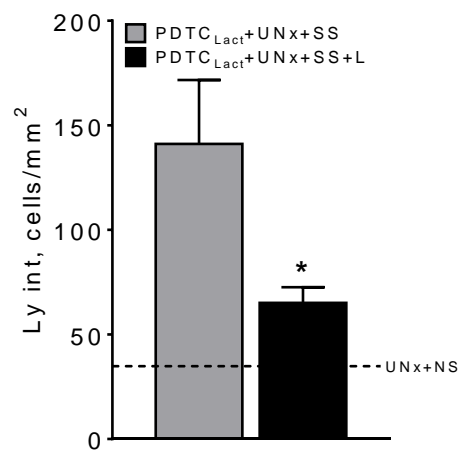

B

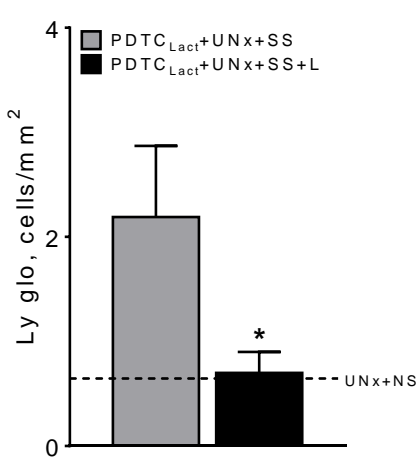

C

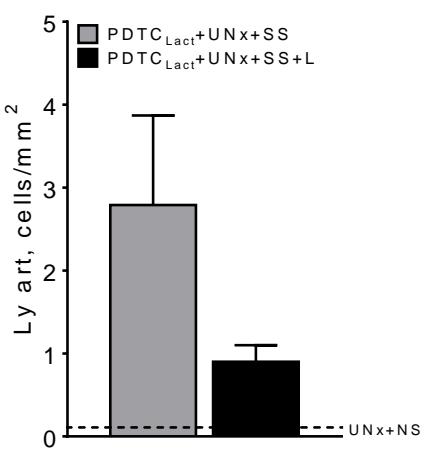

Figura 26. Valores de linfócitos $T$ intersticiais (A), linfócitos $T$ glomerulares $(B)$ e linfócitos $T$ arteriolares (C) dos grupos PDTC Lact $_{+} U N x+S S$ e PDTC Lact $_{+} U N x+S S+L$ com 24 semanas de vida.

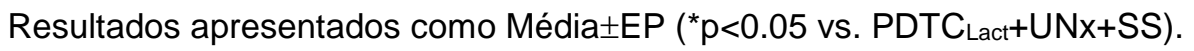

A Tabela 5 e as Figuras 25 e 26 mostram que o tratamento com Losartan atenuou o aumento da infiltração de linfócitos $T$ no interstício renal e nos glomérulos. Assim como nas lesões arteriolares e na infiltração de macrófagos nos vasos, o tratamento com Losartan reduziu apenas numericamente a infiltração de linfócitos no compartimento vascular. 


\section{Sistema renina-angiotensina}

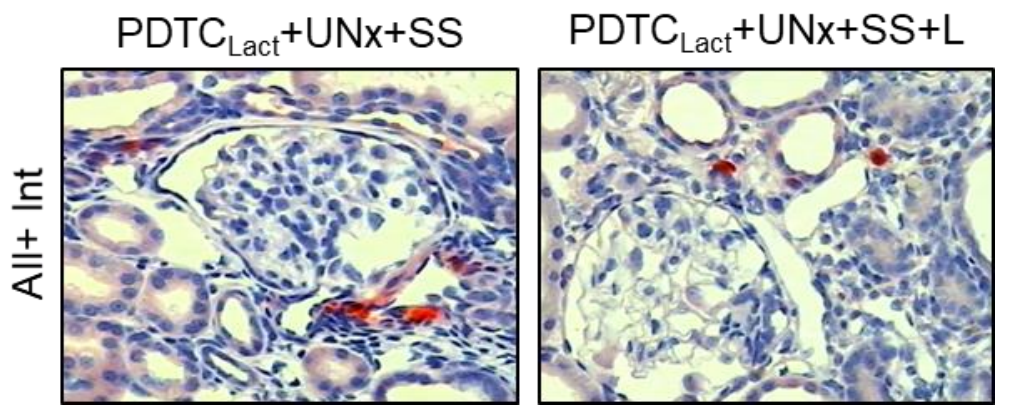

Figura 27. Microfotografias representativas de células positivas para angiotensina II no tecido renal dos grupos PDTC $\mathrm{Lact}_{+} \mathrm{UNx}+\mathrm{SS}$ e PDTC $\mathrm{Lact}_{+} \mathrm{UNx}+\mathrm{SS}+\mathrm{L}$ com 24 semanas de vida. Aumento de $400 x$.

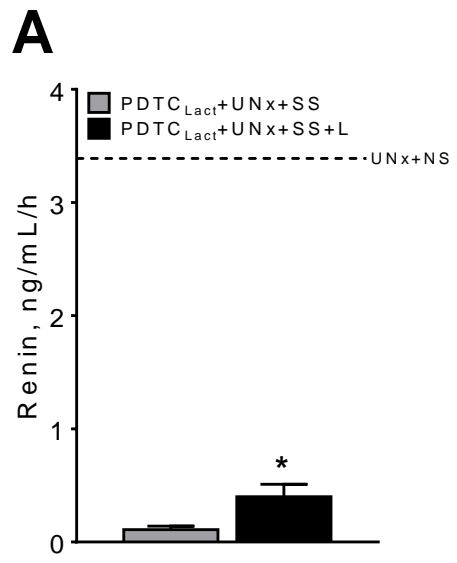

\section{B}

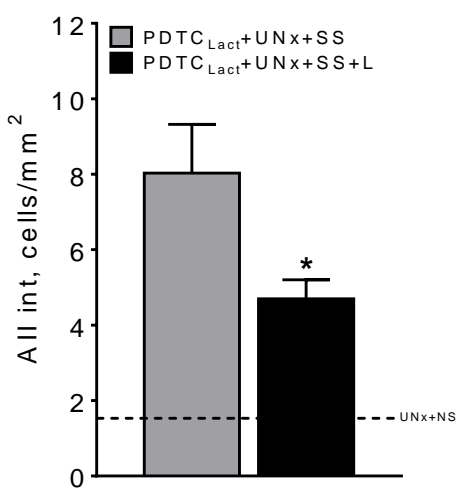

Figura 28. Valores de atividade plasmática de renina (A) e células positivas para Angiotensina II no interstício renal (B) dos grupos PDTC $\mathrm{Lact}_{+} \mathrm{UNx}+\mathrm{SS}$ e PDTC $\mathrm{Lact}_{+} \mathrm{UNx}+\mathrm{SS}+\mathrm{L}$ com 24 semanas de vida. Resultados apresentados como Média \pm EP ( ${ }^{*} p<0.05$ vs. PDTC $\left.L_{\text {Lact }}+U N x+S S\right)$.

No protocolo 1, nós demonstramos que os animais que foram submetidos a SS apresentaram uma profunda queda nos níveis de atividade plasmática de renina. No protocolo 2, os animais de ambos os grupos apresentaram essa mesma queda nos níveis de APR, comparada com os animais UNx+NS (linha tracejada). No entanto, podemos observar que o tratamento com Losartan

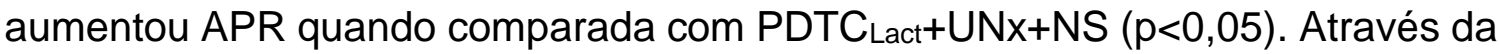
técnica de $\mathrm{IHQ}$, nós analisamos a quantidade de células positivas para All no 
interstício renal, que indica a atividade do SRAA no tecido renal. Os animais tratados com Losartan apresentaram uma diminuição das células positivas para All no interstício renal, indicando que a inibição do SRAA atenua o processo inflamatório nos tecidos renais.

Tabela 6. Vias de sinalização intracelular a estresse oxidativo do protocolo 2

\begin{tabular}{lcc}
\hline & PDTCLact+UNx+SS & PDTCLact+UNx+SS+L \\
& $\mathrm{N}=8$ & $\mathrm{~N}=8$ \\
\hline TLR4 (x UNx+NS) & $3,2 \pm 0,7$ & $1,3 \pm 0,3^{*}$ \\
p65 fosf (x UNx+NS) & $2,1 \pm 0,2$ & $0,8 \pm 0,2^{*}$ \\
IL-6 (x UNx+NS) & $1,8 \pm 0,2$ & $1,1 \pm 0,1^{*}$ \\
HO-1 (x UNx+NS) & $2,1 \pm 0,4$ & $1,1 \pm 0,2^{*}$ \\
MnSOD (x UNx+NS) & $0,4 \pm 0,1$ & $0,6 \pm 0,1$
\end{tabular}

Valores do conteúdo proteico renal de Toll-like receptor (TLR4), conteúdo nuclear de p65 fosforilado no tecido renal (p65 fosf), conteúdo proteico renal de interleucina-6 (IL-6), conteúdo proteico renal de Heme oxygenase 1 (HO-1) e conteúdo proteico renal de Mitochondrial antioxidant manganese superoxide dismutase (MnSOD) dos grupos PDTC $\mathrm{Lact}_{+} \mathrm{UNx}+\mathrm{SS}$ e PDTCLact+UNx+SS+L. Resultados apresentados como Média \pm EP. $\quad\left({ }^{*} \mathrm{p}<0.05\right.$ vs. PDTC $\left.L_{\text {Lact }}+\mathrm{UNx}+\mathrm{SS}\right)$. 


\section{Via de ativação do sistema NF-KB}

\section{A}
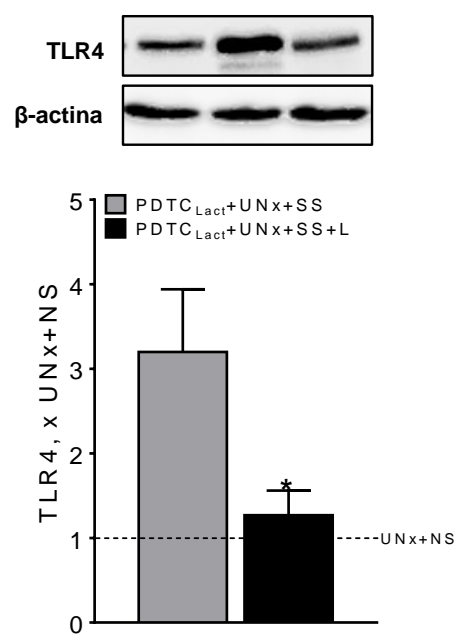

B
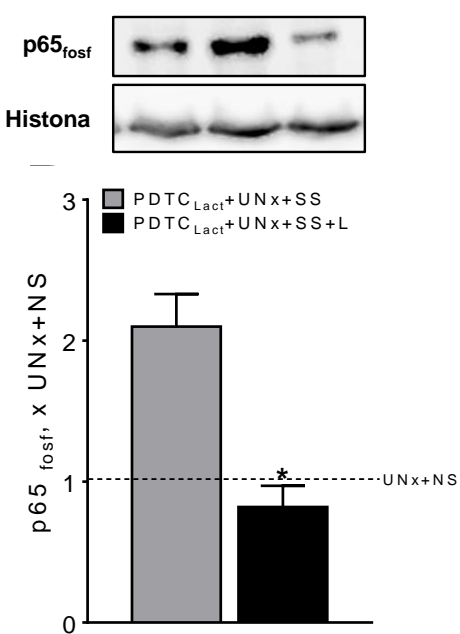
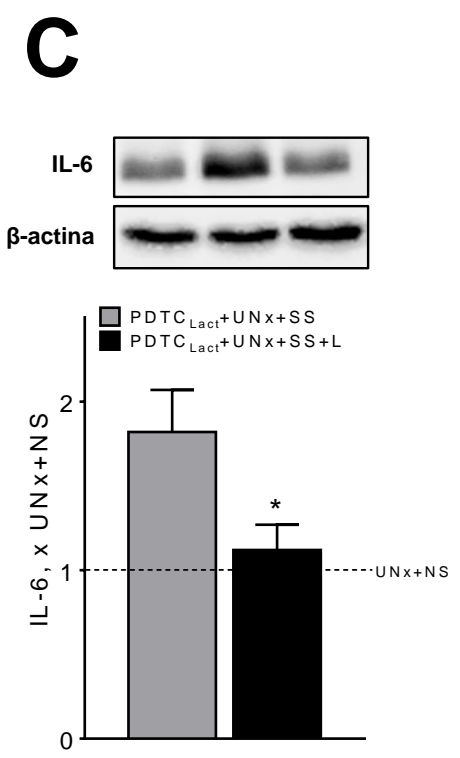

Figura 29. Valores do conteúdo proteico renal de Toll-like receptor (A), conteúdo nuclear de p65 fosforilado no tecido renal (B) e conteúdo proteico renal de interleucina-6 (C) dos grupos

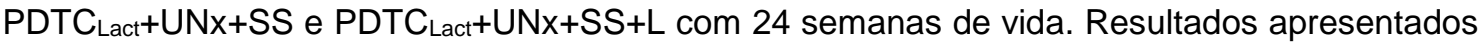
como Média \pm EP ( ${ }^{*} \mathrm{p}<0.05$ vs. PDTC Lact+UNx+SS).

A Tabela 6 e a Figura 29 mostram que, assim como foi observado no protocolo 1, os animais do grupo PDTCLact+UNx+SS apresentaram um aumento no conteúdo renal de TLR4, conteúdo nuclear de p65 fosforilado e conteúdo renal de IL-6. O tratamento com Losartan foi capaz de prevenir o aumento de todos esses parâmetros. 


\section{Estresse oxidativo}
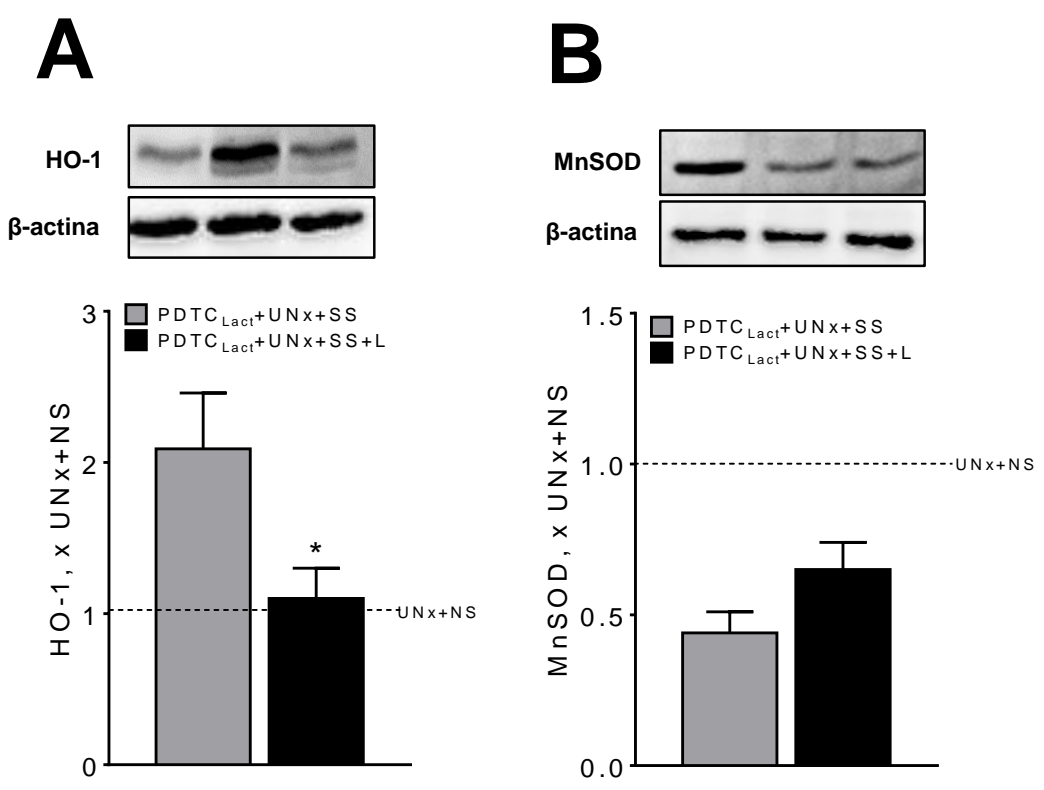

Figura 30. Valores do conteúdo proteico renal de Heme oxygenase 1 (A) e conteúdo proteico renal de Mitochondrial antioxidant manganese superoxide dismutase (B) dos grupos

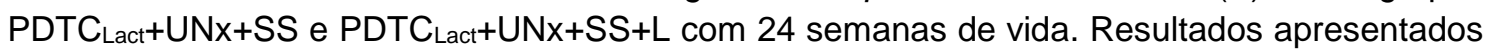
como Média \pm EP $\left({ }^{*} \mathrm{p}<0.05\right.$ vs. PDTC $\left.\mathrm{Lact}_{+}+\mathrm{UNx}+\mathrm{SS}\right)$.

Os dados apresentados na Tabela 6 e na Figura 30 mostram que o tratamento com Losartan reduziu significativamente o conteúdo renal da HO1, porém não preveniu a queda nos níveis de MnSOD no tecido renal, indicando que o Losartan não foi capaz de promover a inibição completa do estresse oxidativo observado nos animais PDTCLact+UNx+SS. 


\section{DISCUSSÃO}

Diferentemente dos humanos, a nefrogênese dos ratos não está completa no momento do nascimento, e continua durante as primeiras duas semanas de vida pós-parto (63). Um estudo anterior de nosso laboratório relatou que, em ratos, a administração do Losartan durante a lactação promove a hipertensão e um quadro de doença renal progressiva na vida adulta (49). Esse estudo corrobora um conceito bem conhecido de que um número reduzido de néfrons no nascimento aumenta o risco de desenvolvimento de hipertensão e doenças cardiovasculares (64). Em 2011, nós descrevemos que o bloqueio do sistema NF-KB (PDTC) na lactação promove hipertensão arterial na fase adulta e fibrose cardíaca, sem, no entanto, apresentar alterações no número de néfrons e lesões renais (53). Apesar da ausência de lesões renais detectáveis, a hipertensão arterial observada nesses animais que receberam PDTC pode ser explicada por uma reabsorção exagerada de sódio e a ativação do sistema reninaangiotensina numa fase mais jovem. Além disso, as alterações na morfologia cardíaca na fase mais tardia podem ser resultado do mecanismo de regulação da pressão arterial.

No presente estudo, nós reproduzimos esse modelo de hipertensão arterial, agora associando a UNx. Ao completarem 24 semanas de vida, os animais do Grupo PDTCLact submetidos a UNx e acompanhados com dieta NS apresentaram aumento da pressão arterial que foi comparável àquela descrita previamente por Canale e cols (53), indicando que a UNx não agravou a hipertensão arterial nesse modelo. Além disso, a UNx não promoveu alterações morfológicas, indicando que a redução na massa renal per si não foi suficiente 
para evidenciar as lesões renais nos ratos com o bloqueio do NF-kB durante a nefrogênese. No entanto, é importante ressaltar que, embora a quantidade de células inflamatórias no tecido renal dos animais PDTCLact+UNx+NS não tenha aumentado em relação aos animais $\mathrm{UNx}+\mathrm{NS}$, a quantidade de macrófagos no interstício renal desses animais mostrou uma correlação positiva com a pressão arterial. Esse dado indica que há um efeito inflamatório latente em decorrência da hipertensão nesse modelo, que poderia ser exacerbado por insultos adicionais, como foi mostrado em estudos anteriores utilizando animais SHR (65).

O aumento da ingestão de sal por si só não é susceptível a causar lesões renais, mas pode agravar alterações iniciadas por outros mecanismos (55). Neste estudo, em ratos acompanhados sem tratamento durante a lactação, a combinação de dois insultos (UNx e SS) resultou em hipertensão moderada, albuminúria e esclerose glomerular, corroborando estudos prévios que associaram a redução de massa renal à sobrecarga salina na dieta $(66,67)$. No entanto não observamos fibrose ou inflamação no interstício renal nos animais deste grupo, indicando que o dano renal causado tem um efeito puramente hemodinâmico, possivelmente envolvendo dano podocitário (68).

Os efeitos da UNx e da SS foram mais graves nos animais que receberam PDTCLact (grupo PDTCLact+UNx+SS). Nesses animais a hipertensão grave foi associada à albuminúria e o surgimento de uma ampla gama de lesões glomerulares, intersticiais e vasculares. Tal como aconteceu nos animais $\mathrm{UNx}+\mathrm{HS}$, os fatores hemodinâmicos parecem ter desempenhado um papel importante no processo de lesão renal, como pode ser observado pela correlação positiva apresentada entre pressão arterial e esclerose glomerular. A 
ação mecânica na parede do capilar glomerular provoca um estiramento anormal, o que provoca um descolamento das células endoteliais, provocando desnudamento da membrana basal e a exposição do colágeno (69). No presente estudo, embora a pressão do capilar glomerular não tenha sido avaliada, é possível que o agravamento das lesões glomerulares no grupo PDTCLact+SS esteja relacionado com a presença de estresse mecânico, como observados em outros modelos de DRC associada a SS $(55,70)$. Além da esclerose glomerular, a mais frequente em DRC, outros tipos de lesões glomerulares foram observados nos animais do grupo PDTCLact+UNx+SS, como a necrose parcial do tufo capilar, lesão esta que está relacionada à formação de micro aneurismas. Esse tipo de lesão glomerular é frequentemente observado em modelos de DRC associada à hipertensão arterial grave, como em ratos submetidos à ablação renal de 5/6 (Nx) associada à inibição do óxido nítrico (71). A formação de micro aneurismas glomerulares também pode estar relacionada ao aumento da pressão intracapilar. Outro tipo de lesão observado no grupo PDTCLact+UNx+SS foi a atrofia glomerular, lesão glomerular descrita por Kriz e colaboradores (68), cuja característica morfológica é a presença de um tufo glomerular de tamanho reduzido, que se mantém ligado ao polo vascular, enquanto o espaço urinário se apresenta extremamente dilatado. A atrofia glomerular leva à redução do número de néfrons, colaborando com a perda contínua da função renal, como foi observado na fase tardia do modelo Nx (72). Um tipo de lesão glomerular menos frequente nos modelos experimentais de DRC é a formação de microtrombos nos capilares glomerulares, que está relacionada com lesão do endotélio vascular. Esse tipo de lesão glomerular foi também observado nos animais do grupo PDTCLact+UNx+SS, sugerindo que a sobrecarga salina acentua os 
distúrbios do endotélio vascular. Em ratos Nx, o bloqueio do VEGF (vascular endothelial growth factor) exacerba as lesões glomerulares decorrentes da formação de microtrombos, que podem evoluir para uma esclerose glomerular (73). Sabe-se que o VEGF participa da vasculogênese $(74,75)$ e há dados recentes na literatura indicando que o sistema NF-kB pode ser um dos reguladores da expressão dos receptores do $\operatorname{VEGF}(76,77)$. Considerando esses dados, podemos supor que o bloqueio do NF-kB durante a nefrogênese tenha resultado em um distúrbio do endotélio vascular decorrente da alteração na atividade regulatória do VEGF. Em consonância com essas informações, os animais $\mathrm{PDTC}_{\mathrm{Lact}}+\mathrm{UNx}+\mathrm{SS}$ apresentaram lesões vasculares, com proliferação das células miointimais e necrose fibrinóide, que estão associadas à HA grave, como foi observado em modelos de inibição crônica de óxido nítrico com sobrecarga salina (57).

Além das alterações hemodinâmicas, os fenômenos inflamatórios participam do agravamento da $\mathrm{HA}$ e mecanismos de lesão renal na DRC. A produção de citocinas e quimiocinas, o influxo de células inflamatórias, a proliferação celular e a infiltração do interstício renal por miofibroblastos são eventos que terminam por levar ao acúmulo de matriz extracelular e ao desenvolvimento de fibrose renal $(6,9)$. A inflamação incipiente que os animais do grupo PDTCLact+UNx+NS apresentaram também foi exacerbada com a administração da dieta SS, e provavelmente contribuiu para o agravamento das lesões glomerulares e arteriolares observadas nos animais do grupo

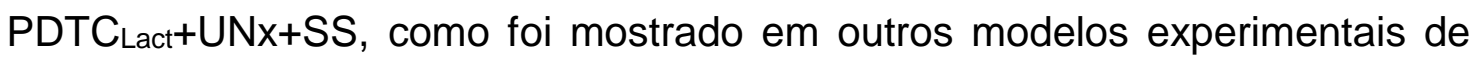
DRC $(3,7,54,78)$. Também observamos nesses animais uma intensa elevação dos níveis séricos de MCP-1, uma citocina chave para o recrutamento de 
macrófagos. A dieta SS resultou em um intenso infiltrado macrofágico e linfocitário no tecido renal dos animais do grupo PDTCLact+UNx+SS, principalmente no compartimento intersticial, com correlação positiva entre a quantidade de linfócitos intersticiais e albuminúria. Além da infiltração de células inflamatórias, observamos um aumento na deposição de colágeno tipo I no córtex renal, indicando que há um processo avançado de estabelecimento da DRC com a presença de fibrose no tecido renal. O impacto deste processo na função renal pode ser verificado com a diminuição do clearance de creatinina.

Como demonstrado em vários modelos experimentais de DRC, o sistema NF-kB exerce um papel fundamental na patogênese da DRC $(44,78)$, ativando a transcrição de uma série de agentes pró-inflamatórios. No presente estudo, mostramos aumento expressivo na atividade do sistema NF-kB (translocação

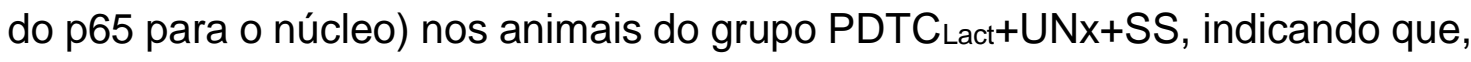
paradoxalmente, a inibição desse sistema durante a lactação resultou em uma ativação exacerbada em resposta a UNx e a dieta HS na fase adulta. Esses resultados sugerem que o sistema NF-kB participa da organogênese do rim e que uma vez inibido durante a nefrogênese há uma exacerbação a sensibilidade a sal na fase adulta, progredindo para DRC. Sabe-se que a ativação do sistema NF-KB induz a expressão de agentes pró inflamatórios como interleucinas e moléculas de adesão, levando a um processo crônico de inflamação e a fibrose intersticial $(44,78,79)$. Vários são os estímulos que podem contribuir para a ativação do sistema NF-kB nos animais do grupo PDTCLact+UNx+SS, como o aumento da expressão renal do receptor TLR-4. A ativação da cascata do NFKB também pode ser resultado da presença de estresse oxidativo no tecido renal. Estudos recentes têm demonstrado o papel do estresse oxidativo em 
diversos modelos experimentais de HT associada a dano renal $(80,81)$. Nos animais do grupo PDTCLact+UNx+SS um indicativo da ocorrência do estresse oxidativo no tecido renal é um aumento do conteúdo proteico da HO-1 e, simultaneamente, redução do MnSOD renal, que são duas enzimas associadas a resposta tecidual ao estresse oxidativo na hipertensão e na DRC (60-62).

Há evidências de que a All exerce efeito pro-inflamatório no tecido renal estimulando localmente a produção de quimiocinas/citocinas através da ativação do sistema NF-kB $(27,79,82)$. Esse processo inflamatório contribui na patogênese da HA e DRC, o que já foi evidenciado em outros modelos de DRC que receberam SS $(70,83,84)$. Nesse contexto, o SRAA tem um papel fundamental na progressão da DRC, tanto com o seu efeito como vasoconstrictor como pró-inflamatório. Embora a SS tenha reduzido drasticamente a renina circulante, células positivas para All estavam presentes no interstício renal, possivelmente produzida por algumas células inflamatórias, como foi descrito por Nataraj (12). A relevância da atividade intrarenal da All na patogênese da DRC já foi descrita em outros estudos $(38,85)$. Os nossos achados sugerem que o processo fibrótico renal observado nos ratos PDTCLact+UNx+SS está associado à ativação de várias vias inflamatórias que envolvem os sistemas SRAA e NF-kB, e para evidenciar o papel da All nesse modelo utilizamos um conhecido antagonista do receptor AT-1 (Losartan) nos animais PDTCLact submetidos a UNx e SS.

O tratamento com Losartan promoveu uma renoproteção parcial, associada à redução na pressão arterial, lesões glomerulares e depósito de colágeno no interstício renal. Além disso, os fenômenos inflamatórios como infiltrado macrofágico, de linfócitos $T$ e células positivas para All foram 
significativamente reduzidos. Esses achados corroboram os dados da literatura que indicam que o tratamento com bloqueadores de AT1 ou com antiinflamatórios atenua as lesões renais associadas à redução das células inflamatórias $(55,70,84)$. Além disso, o tratamento com Losartan preveniu a translocação de p65 para o núcleo, indicando a inibição da atividade do sistema NF-KB. Esses achados estão de acordo com os inúmeros dados na literatura que relacionam a inibição dessa via de sinalização com a redução nas lesões renais nos modelos de DRC $(44,78)$. No entanto, o tratamento com Losartan não foi eficiente em promover redução nas lesões arteriolares deste modelo, sugerindo que outros mecanismos podem estar envolvidos no dano vascular nesses animais.

Em resumo, o presente estudo corrobora a descoberta de que os animais que receberam PDTC durante a lactação apresentam hipertensão arterial e pequenas alterações renais na vida adulta. Além disso, mostramos que, após a UNx, o rim destes animais apresenta sinais de inflamação incipiente. A adição da SS desmascara a vulnerabilidade do tecido renal ao estresse mecânico, o que se traduz num quadro inflamatório e graves lesões glomerulares, intersticiais e vasculares, mostrando semelhança com quadros de hipertensão maligna. Em um aparente paradoxo, a ativação do sistema NF-kB, possivelmente através do receptor TLR4, estresse oxidativo e produção local de All, pode desempenhar um papel fundamental na patogênese da lesão renal neste modelo. 


\section{CONCLUSÕES}

- A sobrecarga salina associada a UNx acentua a hipertensão arterial e torna evidente a existência de uma disfunção renal no modelo de hipertensão decorrente do bloqueio de NF-kB durante a nefrogênese;

- As lesões renais decorrentes da UNx e dieta HS estão associadas a uma ativação da via de sinalização que envolve a All e NF-kB;

- O bloqueio dos receptores AT1 promove renoproteção parcial, e inibe a ativação do sistema NF-KB, evidenciando a importância patogênica deste último. 


\section{REFERÊNCIAS BIBLIOGRÁFICAS}

1. Sesso RC, Lopes AA, Thomé FS, Lugon JR, Martins CT. Brazilian Chronic Dialysis Survey 2016. J Bras Nefrol. 2017;39(3):261-6.

2. Anderson JA, Lentsch AB, Hadjiminas DJ, Miller FN, Martin AW, Nakagawa K, et al. The role of cytokines, adhesion molecules, and chemokines in interleukin-2-induced lymphocytic infiltration in C57BL/6 mice. J Clin Invest. 1996;97(8):1952-9.

3. Fujihara CK, Malheiros DM, Zatz R, Noronha IL. Mycophenolate mofetil attenuates renal injury in the rat remnant kidney. Kidney Int. 1998;54(5):1510-9.

4. Anderson S, Meyer TW, Rennke HG, Brenner BM. Control of glomerular hypertension limits glomerular injury in rats with reduced renal mass. J Clin Invest. 1985;76(2):612-9.

5. Shankland SJ, Ly H, Thai K, Scholey JW. Increased glomerular capillary pressure alters glomerular cytokine expression. Circ Res. $1994 ; 75(5): 844-53$.

6. Hisada $Y$, Sugaya $T$, Yamanouchi M, Uchida H, Fujimura H, Sakurai $\mathrm{H}$, et al. Angiotensin II plays a pathogenic role in immune-mediated renal injury in mice. The Journal of clinical investigation. 1999;103(5):627-35.

7. Johnson RJ, Alpers CE, Yoshimura A, Lombardi D, Pritzl P, Floege $\mathrm{J}$, et al. Renal injury from angiotensin II-mediated hypertension. Hypertension. 1992;19(5):464-74.

8. Kagami S, Border WA, Miller DE, Noble NA. Angiotensin II stimulates extracellular matrix protein synthesis through induction of transforming 
growth factor-beta expression in rat glomerular mesangial cells. The Journal of clinical investigation. 1994;93(6):2431-7.

9. Ruiz-Ortega M, Bustos C, Hernandez-Presa MA, Lorenzo O, Plaza JJ, Egido J. Angiotensin II participates in mononuclear cell recruitment in experimental immune complex nephritis through nuclear factor-kappa B activation and monocyte chemoattractant protein-1 synthesis. J Immunol. 1998;161(1):430-9.

10. Grafe M, Auch-Schwelk W, Zakrzewicz A, Regitz-Zagrosek V, Bartsch P, Graf K, et al. Angiotensin II-induced leukocyte adhesion on human coronary endothelial cells is mediated by E-selectin. Circulation research. 1997;81(5):804-11

11. Tummala PE, Chen $\mathrm{XL}$, Sundell $\mathrm{CL}$, Laursen JB, Hammes $\mathrm{CP}$, Alexander RW, et al. Angiotensin II induces vascular cell adhesion molecule-1 expression in rat vasculature: A potential link between the renin-angiotensin system and atherosclerosis. Circulation. 1999;100(11):1223-9.

12. Nataraj C, Oliverio MI, Mannon RB, Mannon PJ, Audoly LP, Amuchastegui CS, et al. Angiotensin II regulates cellular immune responses through a calcineurin-dependent pathway. J Clin Invest. 1999;104(12):1693-701.

13. Wu LL, Yang N, Roe CJ, Cooper ME, Gilbert RE, Atkins RC, et al. Macrophage and myofibroblast proliferation in remnant kidney: role of angiotensin II. Kidney Int Suppl. 1997;63:S221-5.

14. Mervaala EM, Muller DN, Park JK, Schmidt F, Lohn M, Breu V, et al. Monocyte infiltration and adhesion molecules in a rat model of high human renin hypertension. Hypertension. 1999;33(1 Pt 2):389-95. 
15. Tanaka R, Sugihara K, Tatematsu A, Fogo A. Internephron heterogeneity of growth factors and sclerosis--modulation of platelet-derived growth factor by angiotensin II. Kidney international. 1995;47(1):131-9.

16. Luvara G, Pueyo ME, Philippe M, Mandet C, Savoie F, Henrion D, et al. Chronic blockade of NO synthase activity induces a proinflammatory phenotype in the arterial wall: prevention by angiotensin II antagonism. Arterioscler Thromb Vasc Biol. 1998;18(9):1408-16.

17. Monteiro de Freitas AS, Coimbra TM, Costa RS, Baroni EA. Urinary transforming growth factor-beta (TGF-beta) excretion and renal production of TGF-beta in rats with subtotal renal ablation: effect of enalapril and nifedipine. Nephron. 1998;78(3):302-9.

18. Wu LL, Cox A, Roe CJ, Dziadek M, Cooper ME, Gilbert RE. Transforming growth factor beta 1 and renal injury following subtotal nephrectomy in the rat: role of the renin-angiotensin system. Kidney Int. 1997;51(5):1553-67.

19. Taal MW, Zandi-Nejad K, Weening B, Shahsafaei A, Kato S, Lee $\mathrm{KW}$, et al. Proinflammatory gene expression and macrophage recruitment in the rat remnant kidney. Kidney international. 2000;58(4):1664-76.

20. Goncalves AR, Fujihara CK, Mattar AL, Malheiros DM, Noronha Ide L, de Nucci G, et al. Renal expression of COX-2, ANG II, and AT1 receptor in remnant kidney: strong renoprotection by therapy with losartan and a nonsteroidal anti-inflammatory. Am J Physiol Renal Physiol. 2004;286(5):F94554. 
21. Fujihara CK, Velho M, Malheiros DM, Zatz R. An extremely high dose of losartan affords superior renoprotection in the remnant model. Kidney Int. 2005;67(5):1913-24.

22. Sadoshima J, Qiu Z, Morgan JP, Izumo S. Angiotensin II and other hypertrophic stimuli mediated by $G$ protein-coupled receptors activate tyrosine kinase, mitogen-activated protein kinase, and 90-kD S6 kinase in cardiac myocytes. The critical role of $\mathrm{Ca}(2+)$-dependent signaling. Circulation research. 1995;76(1):1-15.

23. Kranzhofer R, Browatzki M, Schmidt J, Kubler W. Angiotensin II activates the proinflammatory transcription factor nuclear factor-kappaB in human monocytes. Biochemical and biophysical research communications. 1999;257(3):826-8.

24. Gomez-Garre D, Largo R, Tejera N, Fortes J, Manzarbeitia F, Egido J. Activation of NF-kappaB in tubular epithelial cells of rats with intense proteinuria: role of angiotensin $\|$ and endothelin-1. Hypertension. $2001 ; 37(4): 1171-8$.

25. Esteban V, Ruperez M, Vita JR, Lopez ES, Mezzano S, Plaza JJ, et al. Effect of simultaneous blockade of AT1 and AT2 receptors on the NFkappaB pathway and renal inflammatory response. Kidney Int Suppl. 2003(86):S33-8.

26. Mezzano S, Aros C, Droguett A, Burgos ME, Ardiles L, Flores C, et al. NF-kappaB activation and overexpression of regulated genes in human diabetic nephropathy. Nephrology, dialysis, transplantation : official publication of the European Dialysis and Transplant Association - European Renal Association. 2004;19(10):2505-12. 
27. Wolf G, Wenzel U, Burns KD, Harris RC, Stahl RA, Thaiss F. Angiotensin II activates nuclear transcription factor-kappaB through AT1 and AT2 receptors. Kidney international. 2002;61(6):1986-95.

28. Wolf G, Schneider A, Helmchen U, Stahl RA. AT1-receptor antagonists abolish glomerular MCP-1 expression in a model of mesangial proliferative glomerulonephritis. Experimental nephrology. 1998;6(2):112-20.

29. Li XC, Zhuo JL. Intracellular ANG II directly induces in vitro transcription of TGF-beta1, MCP-1, and NHE-3 mRNAs in isolated rat renal cortical nuclei via activation of nuclear AT1a receptors. Am J Physiol Cell Physiol. 2008;294(4):C1034-45.

30. Piecha G, Koleganova N, Gross ML, Geldyyev A, Adamczak M, Ritz E. Regression of glomerulosclerosis in subtotally nephrectomized rats: effects of monotherapy with losartan, spironolactone, and their combination. Am J Physiol Renal Physiol. 2008;295(1):F137-44.

31. Henkel T, Machleidt T, Alkalay I, Kronke M, Ben-Neriah Y, Baeuerle PA. Rapid proteolysis of I kappa B-alpha is necessary for activation of transcription factor NF-kappa B. Nature. 1993;365(6442):182-5.

32. Couser WG. Basic and translational concepts of immune-mediated glomerular diseases. J Am Soc Nephrol. 2012;23(3):381-99.

33. Goncalves GM, Castoldi A, Braga TT, Camara NO. New roles for innate immune response in acute and chronic kidney injuries. Scandinavian journal of immunology. 2011;73(5):428-35.

34. Rovin BH, Dickerson JA, Tan LC, Hebert CA. Activation of nuclear factor-kappa B correlates with MCP-1 expression by human mesangial cells. Kidney international. 1995;48(4):1263-71. 
35. Wong SC, Fukuchi M, Melnyk P, Rodger I, Giaid A. Induction of cyclooxygenase-2 and activation of nuclear factor-kappaB in myocardium of patients with congestive heart failure. Circulation. 1998;98(2):100-3.

36. Liu SF, Ye X, Malik AB. Inhibition of NF-kappaB activation by pyrrolidine dithiocarbamate prevents In vivo expression of proinflammatory genes. Circulation. 1999;100(12):1330-7.

37. Spink J, Cohen J, Evans TJ. The cytokine responsive vascular smooth muscle cell enhancer of inducible nitric oxide synthase. Activation by nuclear factor-kappa B. The Journal of biological chemistry. 1995;270(49):295417.

38. Muller DN, Dechend R, Mervaala EM, Park JK, Schmidt F, Fiebeler A, et al. NF-kappaB inhibition ameliorates angiotensin II-induced inflammatory damage in rats. Hypertension. 2000;35(1 Pt 2):193-201.

39. Barnes PJ, Karin M. Nuclear factor-kappaB: a pivotal transcription factor in chronic inflammatory diseases. The New England journal of medicine. 1997;336(15):1066-71.

40. Mezzano SA, Barria M, Droguett MA, Burgos ME, Ardiles LG, Flores C, et al. Tubular NF-kappaB and AP-1 activation in human proteinuric renal disease. Kidney international. 2001;60(4):1366-77.

41. Sahali D, Pawlak A, Le Gouvello S, Lang P, Valanciute A, Remy P, et al. Transcriptional and post-transcriptional alterations of IkappaBalpha in active minimal-change nephrotic syndrome. Journal of the American Society of Nephrology : JASN. 2001;12(8):1648-58.

42. Hofmann MA, Schiekofer S, Isermann B, Kanitz M, Henkels M, Joswig $\mathrm{M}$, et al. Peripheral blood mononuclear cells isolated from patients with 
diabetic nephropathy show increased activation of the oxidative-stress sensitive transcription factor NF-kappaB. Diabetologia. 1999;42(2):222-32.

43. Gong R, Rifai A, Tolbert EM, Biswas P, Centracchio JN, Dworkin LD. Hepatocyte growth factor ameliorates renal interstitial inflammation in rat remnant kidney by modulating tubular expression of macrophage chemoattractant protein-1 and RANTES. Journal of the American Society of Nephrology : JASN. 2004;15(11):2868-81.

44. Fujihara CK, Antunes GR, Mattar AL, Malheiros DM, Vieira JM, Jr., Zatz R. Chronic inhibition of nuclear factor-kappaB attenuates renal injury in the 5/6 renal ablation model. American journal of physiology Renal physiology. 2007;292(1):F92-9.

45. Boyle EM, Jr., Kovacich JC, Canty TG, Jr., Morgan EN, Chi E, Verrier ED, et al. Inhibition of nuclear factor-kappa B nuclear localization reduces human E-selectin expression and the systemic inflammatory response. Circulation. 1998;98(19 Suppl):II282-8.

46. Marui N, Offermann MK, Swerlick R, Kunsch C, Rosen CA, Ahmad $\mathrm{M}$, et al. Vascular cell adhesion molecule-1 (VCAM-1) gene transcription and expression are regulated through an antioxidant-sensitive mechanism in human vascular endothelial cells. The Journal of clinical investigation. 1993;92(4):186674.

47. Hilgers KF, Norwood VF, Gomez RA. Angiotensin's role in renal development. Semin Nephrol. 1997;17(5):492-501 .

48. Tufro-McReddie A, Romano LM, Harris JM, Ferder L, Gomez RA. Angiotensin II regulates nephrogenesis and renal vascular development. Am J Physiol. 1995;269(1 Pt 2):F110-5. 
49. Machado FG, Poppi EP, Fanelli C, Malheiros DM, Zatz R, Fujihara CK. AT1 blockade during lactation as a model of chronic nephropathy: mechanisms of renal injury. American journal of physiology Renal physiology. 2008;294(6):F1345-53.

50. Chen F, Castranova V, Shi X. New insights into the role of nuclear factor-kappaB in cell growth regulation. Am J Pathol. 2001;159(2):387-97.

51. Bushdid PB, Brantley DM, Yull FE, Blaeuer GL, Hoffman LH, Niswander L, et al. Inhibition of NF-kappaB activity results in disruption of the apical ectodermal ridge and aberrant limb morphogenesis. Nature. 1998;392(6676):615-8.

52. Kanegae Y, Tavares AT, Izpisua Belmonte JC, Verma IM. Role of Rel/NF-kappaB transcription factors during the outgrowth of the vertebrate limb. Nature. 1998;392(6676):611-4.

53. Canale D, Rodrigues MV, Ferreira DN, Machado FG, Veras MM, Malheiros DM, et al. Programmed hypertension in rats treated with a NF-kappaB inhibitor during nephrogenesis: renal mechanisms. Hypertension research : official journal of the Japanese Society of Hypertension. 2011;34(6):693-700.

54. Utimura R, Fujihara CK, Mattar AL, Malheiros DM, Noronha IL, Zatz $\mathrm{R}$, et al. Mycophenolate mofetil prevents the development of glomerular injury in experimental diabetes. Kidney Int. 2003;63(1):209-16.

55. Fujihara CK, Michellazzo SM, de Nucci G, Zatz R. Sodium excess aggravates hypertension and renal parenchymal injury in rats with chronic NO inhibition. The American journal of physiology. 1994;266(5 Pt 2):F697-705. 
56. Mancini G, Carbonara AO, Heremans JF. Immunochemical quantitation of antigens by single radial immunodiffusion. Immunochemistry. 1965;2(3):235-54.

57. Fujihara CK, Avancini Costa Malheiros DM, de Lourdes Noronha II, De Nucci G, Zatz R. Mycophenolate Mofetil Reduces Renal Injury in the Chronic Nitric Oxide Synthase Inhibition Model. Hypertension. 2001;37(1):170-5.

58. Jepsen FL, Mortensen PB. Interstitial fibrosis of the renal cortex in minimal change lesion and its correlation with renal function. A quantitative study. Virchows Arch A Pathol Anat Histol. 1979;383(3):265-70.

59. Wallenstein S, Zucker CL, Fleiss JL. Some statistical methods useful in circulation research. Circ Res. 1980;47(1):1-9.

60. Willis D, Moore AR, Frederick R, Willoughby DA. Heme oxygenase: a novel target for the modulation of the inflammatory response. Nat Med. 1996;2(1):87-90.

61. Rodriguez-Iturbe B, Sepassi L, Quiroz Y, Ni Z, Wallace DC, Vaziri ND. Association of mitochondrial SOD deficiency with salt-sensitive hypertension and accelerated renal senescence. J Appl Physiol (1985). 2007;102(1):255-60.

62. Correa-Costa M, Azevedo H, Amano MT, Gonçalves GM, Hyane MI, Cenedeze MA, et al. Transcriptome analysis of renal ischemia/reperfusion injury and its modulation by ischemic pre-conditioning or hemin treatment. PLoS One. 2012;7(11):e49569.

63. Moritz KM, Wintour EM. Functional development of the meso- and metanephros. Pediatr Nephrol. 1999;13(2):171-8.

64. Brenner BM, Garcia DL, Anderson S. Glomeruli and blood pressure. Less of one, more the other? Am J Hypertens. 1988;1(4 Pt 1):335-47. 
65. Rodríguez-Iturbe B, Quiroz Y, Ferrebuz A, Parra G, Vaziri ND. Evolution of renal interstitial inflammation and NF-kappaB activation in spontaneously hypertensive rats. Am J Nephrol. 2004;24(6):587-94.

66. M C. Uninephrectomy in young age or chronic salt loading causes salt-sensitive hypertension in adult rats. In: Sällström J SO, Larsson E, Persson AE . editor. Hypertension2007. p. 1342-50.

67. Rodríguez-Gómez I, Wangensteen R, Pérez-Abud R, Quesada A, Del Moral RG, Osuna A, et al. Long-term consequences of uninephrectomy in male and female rats. Hypertension. 2012;60(6):1458-63.

68. Kriz W, Hosser H, Hahnel B, Gretz N, Provoost AP. From segmental glomerulosclerosis to total nephron degeneration and interstitial fibrosis: a histopathological study in rat models and human glomerulopathies. Nephrology, dialysis, transplantation : official publication of the European Dialysis and Transplant Association - European Renal Association. 1998;13(11):2781-98.

69. Lee LK, Meyer TW, Pollock AS, Lovett DH. Endothelial cell injury initiates glomerular sclerosis in the rat remnant kidney. The Journal of clinical investigation. 1995;96(2):953-64.

70. Chandramohan G, Bai Y, Norris K, Rodriguez-Iturbe B, Vaziri ND. Effects of dietary salt on intrarenal angiotensin system, $\mathrm{NAD}(\mathrm{P}) \mathrm{H}$ oxidase, COX2, MCP-1 and PAl-1 expressions and NF-kappaB activity in salt-sensitive and resistant rat kidneys. American journal of nephrology. 2008;28(1):158-67.

71. Fujihara CK, De Nucci G, Zatz R. Chronic nitric oxide synthase inhibition aggravates glomerular injury in rats with subtotal nephrectomy. Journal of the American Society of Nephrology : JASN. 1995;5(7):1498-507. 
72. Fujihara CK, Noronha IL, Malheiros, Antunes GR, de Oliveira IB, Zatz R. Combined mycophenolate mofetil and losartan therapy arrests established injury in the remnant kidney. Journal of the American Society of Nephrology : JASN. 2000;11(2):283-90.

73. Machado FG, Kuriki PS, Fujihara CK, Fanelli C, Arias SC, Malheiros DM, et al. Chronic VEGF blockade worsens glomerular injury in the remnant kidney model. PloS one. 2012;7(6):e39580.

74. Kitamoto $\mathrm{Y}$, Tokunaga H, Tomita K. Vascular endothelial growth factor is an essential molecule for mouse kidney development: glomerulogenesis and nephrogenesis. The Journal of clinical investigation. 1997;99(10):2351-7 .

75. Tufro A, Norwood VF, Carey RM, Gomez RA. Vascular endothelial growth factor induces nephrogenesis and vasculogenesis. Journal of the American Society of Nephrology : JASN. 1999;10(10):2125-34.

76. Greenberger S, Adini I, Boscolo E, Mulliken JB, Bischoff J. Targeting NF-kappaB in infantile hemangioma-derived stem cells reduces VEGFA expression. Angiogenesis. 2010;13(4):327-35.

77. Klettner A, Westhues D, Lassen J, Bartsch S, Roider J. Regulation of constitutive vascular endothelial growth factor secretion in retinal pigment epithelium/choroid organ cultures: p38, nuclear factor kappaB, and the vascular endothelial growth factor receptor-2/phosphatidylinositol 3 kinase pathway. Molecular vision. 2013;19:281-91.

78. Okabe C, Borges RL, de Almeida DC, Fanelli C, Barlette GP, Machado FG, et al. NF-kappaB activation mediates crystal translocation and interstitial inflammation in adenine overload nephropathy. American journal of physiology Renal physiology. 2013;305(2):F155-63. 
79. Han Y, Runge MS, Brasier AR. Angiotensin II induces interleukin-6 transcription in vascular smooth muscle cells through pleiotropic activation of nuclear factor-kappa B transcription factors. Circulation research. 1999;84(6):695-703.

80. Sollinger D, Eißler R, Lorenz S, Strand S, Chmielewski S, Aoqui C, et al. Damage-associated molecular pattern activated Toll-like receptor 4 signalling modulates blood pressure in L-NAME-induced hypertension. Cardiovasc Res. 2014;101(3):464-72.

81. Kitiyakara C, Chabrashvili T, Chen Y, Blau J, Karber A, Aslam S, et al. Salt intake, oxidative stress, and renal expression of NADPH oxidase and superoxide dismutase. J Am Soc Nephrol. 2003;14(11):2775-82.

82. Ruiz-Ortega M, Lorenzo O, Ruperez M, Konig S, Wittig B, Egido J. Angiotensin II activates nuclear transcription factor kappaB through AT(1) and AT(2) in vascular smooth muscle cells: molecular mechanisms. Circulation research. 2000;86(12):1266-72.

83. Tian N, Gu JW, Jordan S, Rose RA, Hughson MD, Manning RD, Jr. Immune suppression prevents renal damage and dysfunction and reduces arterial pressure in salt-sensitive hypertension. American journal of physiology Heart and circulatory physiology. 2007;292(2):H1018-25.

84. Quiroz Y, Pons H, Gordon KL, Rincon J, Chavez M, Parra G, et al. Mycophenolate mofetil prevents salt-sensitive hypertension resulting from nitric oxide synthesis inhibition. American journal of physiology Renal physiology. 2001;281(1):F38-47. 
85. Kobori H, Harrison-Bernard LM, Navar LG. Expression of angiotensinogen mRNA and protein in angiotensin II-dependent hypertension. Journal of the American Society of Nephrology : JASN. 2001;12(3):431-9. 